\title{
Beetles in bamboo forests: community structure in a heterogeneous landscape of southwestern Amazonia
}

\author{
Jennifer M. Jacobs ${ }^{\text {Corresp., }}{ }^{1}$ ， Rudolf von May ${ }^{2}$ ， David H. Kavanaugh ${ }^{3}$ ， Edward F. Connor ${ }^{1}$ \\ 1 Department of Biology, San Francisco State University, San Francisco, California, United States \\ 2 Museum of Zoology, Department of Ecology and Evolutionary Biology, University of Michigan - Ann Arbor, Ann Arbor, Michigan, United States \\ 3 Department of Entomology, California Academy of Sciences, San Francisco, California, USA \\ Corresponding Author: Jennifer M. Jacobs \\ Email address: jmjacobs.berkeley@gmail.com
}

Amazonian bamboo forests dominated by large woody bamboo plants in the genus Guadua cover approximately $180,000 \mathrm{~km}^{2}$ and represent a key resource for many organisms. In southwestern Amazonia, native bamboo forests differ in structure, biodiversity, and growth dynamics from other forest types in the region. However, with the exception of a few species in which habitat specialization or a strong habitat association has been demonstrated, little is known about how bamboo forests influence animal community structure. In an effort to understand more about the animal assemblages associated with Amazonian bamboo forests, we characterized the structure of grounddwelling beetle assemblages living in bamboo forests and adjacent terra firme forests in a lowland rainforest site in Peru. We conducted intensive pitfall trap surveys in 13 bamboo habitat patches and 13 adjacent terra firme habitat patches to determine if there were differences in the abundance and richness of beetle species in these two habitat types. Additionally, given that southwestern Amazonia experiences distinct dry and wet seasons, we conducted our study during the dry and wet season of one year to account for differences in seasonality. We found a distinct beetle assemblage associated with each forest type, and identified a set of dominant species that significantly contributed to the distinctness in beetle community structure between bamboo and terra firme forest. The terra firme forest had a greater number of rare species than the bamboo forest. Several beetle species exhibited a strong association with the bamboo forest, including a large species of Scarabaeidae that appears to be specializing on bamboo. We also found marked differences in beetle assemblages between dry and wet seasons. Our results support the prediction that beetle community structure in bamboo forest differs from that of terra firme in terms of species richness, abundance, and composition. Bamboo-associated animal communities require more exploration and study, and must be included in regional conservation plans seeking to protect entire animal communities in southwestern 
Amazonia. 
Beetles in bamboo forests: community structure in a heterogeneous landscape of southwestern Amazonia

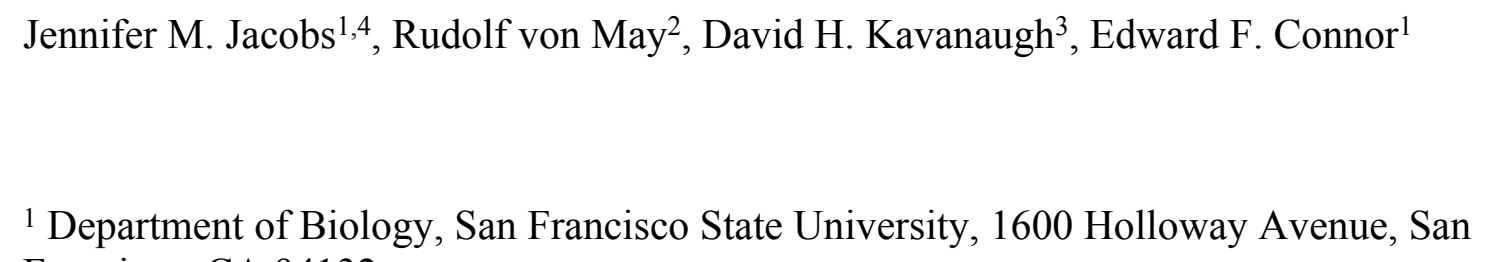

${ }^{1}$ Department of Biology, San Francisco State University, 1600 Holloway Avenue, San Francisco, CA 94132

2 Museum of Zoology, Department of Ecology and Evolutionary Biology, University of Michigan, 2039 Ruthven Museums Building, Ann Arbor, MI 48109-1048

${ }^{3}$ Department of Entomology, California Academy of Sciences, 55 Music Concourse Drive, San Francisco, CA 94118

${ }^{4}$ Corresponding author; e-mail: jmjacobs.berkeley@gmail.com 
47

48

49

50

51

52

53

54

55

56

57

58

59

60

61

62

63

64

65

66

67

68

69

70

71

72

73

74

75

76

77

78

79

80

81

82

83

84

85

86

87

88

89

90

91

92

\begin{abstract}
Amazonian bamboo forests dominated by large woody bamboo plants in the genus Guadua cover approximately $180,000 \mathrm{~km}^{2}$ and represent a key resource for many organisms. In southwestern Amazonia, native bamboo forests differ in structure, biodiversity, and growth dynamics from other forest types in the region. However, with the exception of a few species in which habitat specialization or a strong habitat association has been demonstrated, little is known about how bamboo forests influence animal community structure. In an effort to understand more about the animal assemblages associated with Amazonian bamboo forests, we characterized the structure of ground-dwelling beetle assemblages living in bamboo forests and adjacent terra firme forests in a lowland rainforest site in Peru. We conducted intensive pitfall trap surveys in 13 bamboo habitat patches and 13 adjacent terra firme habitat patches to determine if there were differences in the abundance and richness of beetle species in these two habitat types. Additionally, given that southwestern Amazonia experiences distinct dry and wet seasons, we conducted our study during the dry and wet season of one year to account for differences in seasonality. We found a distinct beetle assemblage associated with each forest type, and identified a set of dominant species that significantly contributed to the distinctness in beetle community structure between bamboo and terra firme forest. The terra firme forest had a greater number of rare species than the bamboo forest. Several beetle species exhibited a strong association with the bamboo forest, including a large species of Scarabaeidae that appears to be specializing on bamboo. We also found marked differences in beetle assemblages between dry and wet seasons. Our results support the prediction that beetle community structure in bamboo forest differs from that of terra firme in terms of species richness, abundance, and composition. Bamboo-associated animal communities require more exploration and study, and must be included in regional conservation plans seeking to protect entire animal communities in southwestern Amazonia.
\end{abstract}


93

94

95

96

97

98

99

100

101

102

103

104

105

106

107

108

109

110

111

112

113

114

115

116

117

118

119

120

121

122

123

124

125

126

127

128

129

130

131

132

133

134

135

136

137

138

\section{Introduction}

Bamboo forests in southwestern Amazonia cover approximately $180,000 \mathrm{~km}^{2}$ and represent the largest bamboo-dominated forest in the Neotropics (Nelson 1994; Griscom and Ashton 2003).

These forests are primarily dominated by woody species in the genus Guadua, a native bamboo that has been present in the region since the pre-Holocene as suggested by fossil evidence (Olivier et al. 2008), or perhaps earlier periods as suggested by recent phylogenetic studies (Ruíz-Sánchez 2011). Many animal species use bamboo habitat for shelter, foraging, reproduction, or a combination of purposes (Emmons and Feer 1990; Louton et al. 1996; Kratter 1997; Dunnum and Salazar-Bravo 2004; Lebbin 2007; von May et al. 2008; von May et al. 2009a; 2009b; 2010; Jacobs and von May 2012; Jacobs et al. 2012), although most of these species also live in other forest types and only a few are considered to be bamboo specialists (Kratter 1997; Davidson et al. 2006a; 2006b; Lebbin et al. 2007).

The dynamics of bamboo forests is relatively well understood, but little is known about the structuring of animal communities associated with bamboo habitat. Most bamboo in southwestern Amazonia grows in patches ranging from less than a hectare up to tens or even thousands of hectares (Griscom and Ashton 2006). Those patches are typically surrounded by upland terra firme or, less frequently, by floodplain forest. Bamboo patches might flower synchronously and then die over large areas, and bamboo plants may or may not recolonize the same areas (Nelson 1994; Griscom and Ashton 2003; Silman 2003; Nelson and Bianchini 2005; Griscom and Ashton 2006; Olivier 2007; 2008). Thus large patches of bamboo may blink in and out of existence over time and space, presenting a dynamic, relatively short-lived resource for other organisms. In this context, it is relevant to investigate how animal communities are structured in bamboo forest compared to neighboring forest types. This question can be empirically addressed by conducting one or more surveys of species richness, composition and abundance in bamboo forest and neighboring forest habitat.

In an effort to understand more about animal communities associated with bamboo forests in southwestern Amazonia, our primary goal in this study was to quantitatively characterize the structure of ground-dwelling beetle assemblages living in bamboo forest and compare them with those of the adjacent terra firme forest. We selected beetles as focal taxa because they are taxonomically and trophically diverse, play vital roles in ecosystem maintenance, serve as an important food source for many vertebrates, and are relatively easy to collect (Didham 1997; Ward and Lariviere 2004). Previous inventories of particular beetle taxa in a variety of habitats in the southeastern portion of the Peruvian Amazon have included minimal sampling in bamboo forests (Pearson and Derr 1986; Erwin 1997; Larsen et al. 2006).

Until recently, with the exception of a small number of herbivorous beetles that are known to specialize on the Guadua plants themselves (T. Erwin, pers. comm.; Anderson 2008) and a large dynastine beetle strongly associated with bamboo (Jacobs et al. 2012), it was not known if other beetle species are closely associated with bamboo forest as a primary habitat, and whether distinct assemblages of beetles are associated with bamboo forests compared to the adjacent terra 
139 firme. Because of the structural differences between these two habitats (Griscom and Ashton $1402003 ; 2006$ ), and the evidence of bamboo specialists in various animal taxa (see summary in

141 Jacobs and von May 2012), we hypothesized that beetle assemblages in bamboo forest would

142 differ from those of terra firme. We predicted that some beetle species would show preferences

143 either for bamboo or terra firme. Additionally, because of seasonal rainfall variation in

144 southeastern Peru, we expected to find differences in beetle community structure between dry

145 and wet seasons. Based on previous findings regarding temporal patterns of insect communities

146 in Neotropical rainforests (Janzen 1973; Pearson and Derr 1986; Richards and Windsor 2007),

147 we hypothesized that beetle species richness and abundance would be greater in the wet season

148 compared to the dry season.

149

150

151

152

\section{Materials and methods}

STUDY SITE - We conducted this study at the Los Amigos Biological Station $\left(12^{\circ} 34^{\prime} 07^{\prime \prime}\right.$ S, 7005'57" W; $270 \mathrm{~m}$ elev.), in Manu province, Madre de Dios region, southeastern Peru (Fig. 1). The Los Amigos Biological Station (hereafter referred to as LA) covers approximately 1,000 ha and borders the Los Amigos Conservation Concession, which covers 145,918 ha of undisturbed

156

157 lowland rainforest including several forest types (von May et al. 2010). Terra firme forest is the dominant habitat in the study area whereas the bamboo habitat occurs in patches of different sizes embedded in terra firme habitat. Annual rainfall is variable and ranges between 2700 and $3000 \mathrm{~mm}$, and $>80 \%$ of the rainfall in this region occurs during the October-May wet season. The dry season, which usually occurs between June and September and has precipitation below or around $100 \mathrm{~mm} / \mathrm{month}$, is relatively cooler than the wet season (http://atrium-biodiversity.org, accessed on 10 April 2014). The mean annual temperature ranges between $21^{\circ} \mathrm{C}$ and $26^{\circ} \mathrm{C}$ (Pitman 2008).

DESIGN OF STUDY - We selected four beetle families for analysis: Scarabaeidae, Carabidae, Histeridae, and Curculionidae. These families represent the majority of the individuals captured in our preliminary sampling. These families also span several functional groups, and include relatively large species, which simplifies curation and identification (Grimbacher and Stork 2009). In addition, we targeted ground-dwelling and understory taxa from these families that would potentially be caught with pitfall traps. In focusing on these families, we were attempting to collect information on decomposers, fruit, seed, and humus eaters, generalist ground foragers, and generalist predators.

We used a paired sampling design with 13 sites, each consisting of one patch of bamboo and an equal sized adjacent area of terra firme. We followed a proportional sampling approach (Schoereder et al. 2004) in which sampling effort was standardized with respect to patch area for bamboo forest and an equal area for terra firme (1 pitfall trap/hectare). Thus, depending on the area of the patch, bamboo patches had different numbers of traps. The terra firme forest received the same number of traps as their "paired" bamboo patches. We sampled each site during two periods in the dry season (July and August 2006) and two periods in the wet season (January and March 2007) to evaluate the effect of seasonality. 
185 to define a sample patch (Fig. 2). However, some patches also contained a second bamboo 186 species, Ichnanthus breviscrobs. Though a few other intermittently distributed bamboo species 187 occur at LA, the upland terraces are dominated by G. weberbaueri (Olivier 2007). We selected

188 sampling sites using Landsat images and vegetation maps used by previous researchers (Lebbin

189 2007; M. Tobler, pers. comm.), and ground-based investigations along the entire trail system at

190 LA $(>100 \mathrm{~km})$. We selected 13 dense patches of bamboo forest, which based on an initial power

191 calculation, was sufficient for statistical analyses. Each bamboo patch and adjacent terra firme

192 habitat (Fig. 2) was considered a site. We estimated the size of the bamboo patch using Arc GIS

1939.1 and a pre-existing vegetation map of LA (Daniel Lebbin, pers. comm.). We also verified the

194 GIS-derived measurements of bamboo patch size with ground observations. Every hectare within

195 a selected bamboo patch, and adjacent terra firme, was allocated one pitfall trap, with patches

196 ranging in size between approximately 1 and 25 ha. The general location of the 13 trap arrays is

197 shown in Fig. 3, and the estimated patch area (ha), number of traps, and GPS coordinates are

198 included in Table S1 (see supplementary material).

199

200

201

202

203

204

205

206

207

208

209

210

211

212

213

214

215

216

217

218

219

220

221

222

223

224

225

226

227

228

229

230

SAMPLING METHODS - We used un-baited pitfall traps to sample beetle communities. Pitfall traps are commonly used to catch surface-active invertebrates and are simple, inexpensive, and yield high numbers of specimens (Ward et al. 2001; Work et al. 2002). The advantage of using unbaited pitfall traps is that they represent a passive capture method to evaluate habitat preference as opposed to trapping with baits which may draw animals from greater distances, potentially outside the bamboo patch. Each pitfall trap consisted of two plastic 16-ounce containers $(12 \mathrm{~cm}$ diameter) stacked together and inserted into the soil so that the top of the containers was flush with the ground. Traps were filled with approximately $0.125 \mathrm{~L}$ of a mixture comprised of $50 \%$ water and 50\% ethanol (95\% solution). A roof composed of palm leaves propped on a stick platform was placed $30 \mathrm{~cm}$ above each trap in order to prevent the traps from being flooded by rainwater or filled by falling leaves and other objects. The leaves covered the trap from above but allowed plenty of room for insects to enter laterally.

At each site, traps were placed 10-30 $\mathrm{m}$ into the bamboo patch, depending on the patch size. We then placed pitfall traps $5 \mathrm{~m}$ apart in either a linear or semi-circular array, depending on the shape, size and accessibility of the bamboo patch. Because Guadua forms extremely dense thickets and each plant is covered with large spines, it was impossible to access all locations within each patch. We always maintained a $5 \mathrm{~m}$ distance between traps regardless of the type of trap array. Our spatial array of traps was relatively similar to trap arrays used in studies by Barbosa and Marquet (2002), Driscoll (2005), and Baker and Barmuta (2006) (Fig. 4). We followed exactly the same procedure for placing traps in the adjacent terra firme. We recorded the location of trap arrays with a Garmin 76 Map GPS in the center portion of the trap array in each habitat at every site. In the largest patch of bamboo $(\sim 25 \mathrm{ha})$, three separate transects of pitfall traps were established because the high density of bamboo culms made it impossible to place all 25 pitfall traps in one transect in the same location. Three separate transects were also established in the terra firme for that particular sampling site.

Pitfall traps were open for seven continuous days in both July and August of 2006 during the dry season, and seven continuous days in both January and March of 2007 during the wet season. Each seven-day period was considered a "sampling period". During the interval between trap openings and closings, traps were monitored by visual inspection in the field for disturbance and 
231 functionality. If traps appeared dry, a small amount of ethanol was added. Traps were always

232 examined following a large storm in case of flooding. For each sampling period, we used a total

233 of 150 traps ( 75 for bamboo and 75 for terra firme), and with four sampling periods we

234 employed a total of 600 traps. For the purpose of analyses and because we were interested in

235

236

237

238

239

240

241

242

243

244

245

246

247

248

249

250

251

252

253

254

255

256

257

258

259

260

261

262

263

264

265

266

267

268

269

270

271

272

273

274

275

276 seasonal patterns, data from July and August were pooled as "dry season" and data from January and March were pooled as "wet season".

SAMPLE PROCESSING - Following trap collection specimens were cleaned, sorted, organized and preserved in jars containing 95\% ethanol. Specimens were pinned, labeled, sorted to morphospecies, and entered into a database. Families, genera, species, and morpho-species were identified with help from a variety of taxonomic resources, including specialists at the California Academy of Sciences, Santa Barbara Natural History Museum, the Smithsonian Institution, and the University of Nebraska (see Acknowledgments). All other beetle specimens and arachnid specimens were kept and set aside for other researchers at the California Academy of Sciences and the Museo de Historia Natural San Marcos in Lima, Peru. Permits to conduct this work and collect specimens were issued by the Instituto Nacional de Recursos Naturales (INRENA), Peru (Research authorizations 053-2005-INRENA-IFFS-DCB, 23-2006-INRENA-IFFS-DCB, 672007-INRENA-IFFS-DCB, and 11-2008-INRENA-IFFS).

ANALYSES -To initially compare patterns of beetle species richness as a function of sampling effort between terra firme and bamboo forest, we generated species accumulation curves (EstimateS 7.5; Colwell 2005). We observed whether the confidence intervals of the curves overlapped to help determine if the communities of beetles in both habitats were different in terms of species richness. Although species accumulation curves are often used to determine the completeness of sampling when conducting an inventory (Longino and Colwell 1997; Longino et al. 2002), they are also helpful in gross comparisons of communities in terms of diversity. Because we maintained exactly the same sampling effort in both habitats, we compared the curves directly and did not need to use richness estimators (Magurran 2004). If the curve of one beetle community in either forest type was lower in species richness than the other forest type, we interpreted that result as a community pattern, not an artifact of under-sampling.

COMPARISON OF BEETLE ASSEMBLAGES BETWEEN FOREST TYPES - To statistically test for overall differences in mean species richness and abundance between the two habitats, we used a paired $t$ test to compare the species richness and abundance of beetles from all families at each pair of sites, while pooling data from dry and wet seasons. We used log transformations to normalize the data for these analyses, and $t$-tests were conducted in SPSS v. 11.0 (Chicago, IL). We also used rank/abundance plots, also known as Whittaker plots, to illustrate contrasts or similarities in patterns of species richness and qualitatively assess the evenness of assemblages (Magurran 2004; Gardner et al. 2007), to compare species abundance distributions in the two habitats. Prior to creating the Whittaker plots, we normalized our data with log-transformations and pooled data from dry and wet seasons.

To characterize the structure of beetle assemblages found in the bamboo and terra firme, we used species composition and abundance data collected in each habitat. However, we first used a Mantel test to test for a correlation between species composition and geographic distance among sites. We used a Bray-Curtis similarity matrix and coupled this with a matrix of all pairwise 
277 distances (in meters) between sites. We used an Excel spreadsheet integrated with PopTools

278 (http://www.cse.csiro.au/poptools) to perform Mantel tests using 1000 randomizations of the

279 distance matrix.

280

281

To compare beetle community structure in bamboo versus terra firme, while pooling across

282 seasons, we conducted a one-way analysis of similarity (ANOSIM; Clarke and Warwick 1994)

283

284

285

286

287

288

289

290

291

292

293

294

295

296

297

298

299

300 using a Bray-Curtis similarity matrix. We used non-metric multidimensional scaling (nMDS; 100 restarts) plots to create graphical representations of ANOSIM results. The distance between points in nMDS plots is proportional to the compositional similarity of those points. Stress values of nMDS plots indicate the "goodness of fit" or quality of the test. Values beginning with zero (perfect fit) through 0.2 are considered effective for interpreting community data. All ANOSIM and nMDS analyses were conducted using a Bray-Curtis similarity matrix based on log-transformed data, with Primer 6.0 (Clarke and Gorley 2006). We also used the application SIMPER (in Primer 6.0), considering each collecting site as a sample and each forest type as a group, to determine which species best characterized each habitat. This procedure initially calculates the species that account for $90 \%$ of the abundance of all species analyzed, and from that list, determines the percentages that each species contributes to the dissimilarity between any two groups.

We conducted a second set of multivariate analyses on each beetle family individually to determine if community structure for every family differed depending on forest type. We compared beetle species composition and abundance in bamboo to that of terra firme for each family (ANOSIM). Data were pooled across seasons.

To compare patterns of abundance or presence/absence of individual species between forest types, we created matched rank-occurrence plots with all species that were represented by at least five individuals. We applied this criterion because it is common that samples of tropical forest invertebrates contain many uncommon species and a substantial percentage of singletons (Coddington et al. 2009). This graphical method allowed us to visualize the degree of overlap between forest types for every species, and illustrate which species were absent, rare, or common in our collection (Longino and Colwell 1997; Delsinne et al. 2008); the exclusion of rare species allowed us to better address differences driven by the most abundant species in the community.

COMPARISON BETWEEN WET AND DRY SEASON - We tested for differences in overall mean species richness and abundance between the dry and wet seasons, using paired $t$-tests. To compare species abundance distributions between dry and wet season, we created Whittaker plots. We identified and ordered the ten most abundant species in each season to compare the identity and rank of the most abundant species during the dry and wet seasons. For both analyses, we pooled data from bamboo and terra firme and used log-transformed data.

To understand how species composition and abundance differed between dry and wet seasons, each within bamboo and terra firme, we used a variety of analyses. To test for seasonal differences in abundance within each forest type, we calculated the difference in number of individuals collected between dry and wet season at all sites for bamboo forest and for terra firme. We then applied a paired $t$-test to determine which forest type exhibited a greater change in beetle abundance between dry and wet season (SPSS v. 11.0, Chicago, IL). To test for 
323 differences in species turnover between seasons in bamboo and terra firme, we performed a

324 similar procedure. We calculated how many species were unique between the dry and wet

325 seasons for each site in the bamboo forest and in terra firme. We then applied a paired $t$-test to

326 the number of unique species in each forest type.

327

328

329

330

331

332

333

334

335

336

337

338

339

340

341

342

343

344

345

346

347

348

349

350

351

352

353

354

355

356

357

358

359

360

361

362

363

364

365

366

367

To further explore the effects of habitat and season on beetle community composition, we performed both one-way and two-way ANOSIM analyses. To test for differences in beetle community composition between forest types in the wet and dry seasons individually, we performed one-way ANOSIM tests and associated nMDS plots. To simultaneously compare the effects of forest type and season on beetle community structure, we ran a two-way ANOSIM test using forest type and season as factors (we did not create an nMDS plot for the two-way ANOSIM because it is difficult to interpret given the more complex structure of the two-factor similarity matrix on which the nMDS analysis is based). The patterns of community structure are best visualized by looking at the one-way nMDS plots for the dry and wet seasons individually. In addition, we created matched rank-occurrence plots to compare patterns of abundance and presence/absence for individual species in the dry and wet seasons. For ANOSIM tests, nMDS plots, and matched rank-occurrence plots, we used species represented by at least five individuals.

\section{Results}

COMPARISON OF BEETLE ASSEMBLAGES BETWEEN FOREST TYPES - The beetle community in bamboo forest differed from that of terra firme in terms of species richness, abundance and composition. We collected a total of 190 species of beetles and 3752 individuals in our target families. In bamboo forest we trapped 120 species of beetles and 1539 individuals, whereas in the terra firme we trapped 141 species of beetles and 2213 individuals (Table S2, see supplementary material). Forty-eight species were found only in bamboo forest, 69 species were found only in terra firme, and 72 species were found in both forest types. Overall, beetles from the family Scarabaeidae comprised the majority of all specimens captured, accounting for $83 \%$ of the total number of individuals and approximately $48 \%$ of all species captured. All families except Histeridae were more species rich in the terra firme by $38 \%, 33 \%$, and $11 \%$, respectively for Carabidae, Curculionidae, and Scarabaeidae. All families except Carabidae were more abundant in the terra firme by $50 \%, 49 \%$ and $45 \%$, respectively for Curculionidae, Histeridae and Scarabaeidae (Table 1 and 2).

Overall, we found significant differences in the mean number of beetle species and individuals in bamboo versus terra firme using data pooled across seasons $\left(t_{12}=2.712, \mathrm{p}=0.019 ; t_{12}=2.088, \mathrm{p}\right.$ $=0.059$, respectively). The species accumulation curves illustrate that the number of species captured in terra firme was higher than that of bamboo forest, but overlapping confidence intervals indicate that the curves did not differ substantially (Fig. 5a). The results shown in Fig. $5 \mathrm{~b}$ would support the idea that, for a given number of individuals sampled in each habitat, the expected number of species would be the same. So the slightly greater number of species of beetles observed in terra firme arises because terra firme forest supports a higher abundance of beetles in these families. 
368 The species abundance distributions in the Whittaker plots for bamboo and terra firme (Fig. 6a)

369 were similar, but terra firme exhibited higher abundances of the most abundant species and a

370 surplus of rare species in comparison to bamboo forest. Though species abundance patterns were

371 similar between bamboo and terra firme habitat, the order of the most dominant species differed

372 between forest types. The ten most abundant species in order of rank abundance in bamboo

373 forest (and displayed as letters on Fig. 6a) were not all the same species, nor were they in the

374 same rank order as those in terra firme.

375

376

377

378

379

380

381

382

383

384

385

386

387

388

389

390

391

392

393

394

395

396

397

398

399

400

401

402

403

404

405

406

407

408

409

410

411

412

413

We did not detect any autocorrelation between differences in beetle assemblages and the distance between sites (Mantel test - Pearson $r=-0.07888, p=0.225$ ). Therefore, we proceeded with multivariate analyses of beetle community structure.

We found significant differences in beetle assemblages between bamboo and terra firme pooling across seasons (ANOSIM Global $\mathrm{R}=0.160, p=0.001$ ). An $\mathrm{nMDS}$ plot (Fig. 7) also suggests the presence of two distinct beetle communities in the bamboo and terra firme, though one terra firme sample from one of the smallest sites ( $1 \mathrm{ha}$ ) is clearly an outlier. A set of 24 beetle species are largely responsible for the dissimilarity of beetle community composition between bamboo and terra firme (Table 3). Four of these species were very abundant only in bamboo forests, and eight other species were very abundant only in terra firme. The remaining 12 species were collected in both habitats but in varied abundances.

For species represented by more than five individuals, matched rank-occurrence plots exhibit varying patterns of abundance and presence/absence in the two habitats (Fig. 8a). Many species exhibited greater abundances in only one forest type. Overall, we found a greater number of the most abundant species in the terra firme compared to the bamboo forest. Beetle species in the family Carabidae and Histeridae appear equally abundant in bamboo and terra firme whereas, Curculionidae and Scarabaeidae exhibited a greater number of species with higher abundances in the terra firme (Fig. 8a).

For two beetle families, community structure also differed between bamboo and terra firme. We detected significant differences in beetle assemblages between bamboo and terra firme for Scarabaeidae and Curculionidae (ANOSIM Global $\mathrm{R}=0.190, p=0.002$; Global $\mathrm{R}=0.154, p=$ 0.003 , respectively), but not for Carabidae and Histeridae (Global $\mathrm{R}=-0.030, p=0.785$; Global $\mathrm{R}=0.044, p=0.187$, respectively).

SEASONALITY AND FOREST TYPE -With data from bamboo and terra firme pooled, overall mean species richness and number of individuals did not significantly differ between dry and wet seasons (paired $-t_{12}=0.907, \mathrm{p}=0.382 ; t_{12}=1.619, \mathrm{p}=0.132$, respectively). However, we collected $10 \%$ more individual beetles in the dry season and $35 \%$ more species in the wet season. Species abundance distributions were similar for the dry and wet season, but the rank-order of the most abundant species changed with the seasons and a greater number of rare species were detected in the wet season (Fig. 6b).

Seasonal differences in abundance and species turnover were greater in terra firme than in bamboo forest. We found a significant difference between the mean number of individuals collected in the dry versus wet seasons in terra firme, compared to that of bamboo forest, across 
414 all sites (paired $-t_{12}=2.951, \mathrm{p}=0.012$ ). Similarly, we found a greater amount of species

415 turnover between the dry versus wet season in terra firme compared to that of bamboo forest $\left(t_{12}\right.$

$416=4.366, \mathrm{p}=0.001)$. A similar pattern was observed when expressing these results as mean

417 difference in number of individuals/trap $\left(t_{12}=2.357, p=0.036\right.$; Fig. $\left.9 a\right)$ and mean number of

418 unique species/trap $\left(t_{12}=3.818, \mathrm{p}=0.002\right.$; Fig. $\left.9 \mathrm{~b}\right)$.

419

420

421

422

Differences in beetle community structure between bamboo and terra firme was more pronounced in the wet season than in the dry season. We found significant differences in beetle community structure in the wet season (ANOSIM Global $\mathrm{R}=0.259, p=0.001$, Figure 10a), with

423

424

425 less distinction between forest types in the dry season (ANOSIM Global $\mathrm{R}=0.068, p=0.070$, Figure 10b). However, the nMDS plot from the dry season illustrates some separation in beetle communities between bamboo and terra firme. One terra firme sampling point that appears to be a distinct outlier (the same site that is an outlier when examining data pooled among seasons, Figure 5), may be influencing the results. The results of the two-way ANOSIM suggest that both forest type and season significantly affect beetle community structure, although the effect of seasonality was slightly stronger than that of forest type (season: Global $R=0.298, p=0.001$, forest type: Global $\mathrm{R}=0.163, \mathrm{p}=0.001$ ).

431

432

Matched rank-occurrence plots illustrate the variation in abundance for individual species, with more than five individuals captured, in the dry and wet seasons (Fig. 8b). Species in the family Carabidae were found primarily in the wet season, Curculionidae and Histeridae did not show strong seasonal variation, and we trapped more species of Scarabaeidae with higher abundances

436 in the dry season. For a complete list of all species, where they were collected (forest type) and when they were collected (season) see Online Resource 1.

438

439

\section{Discussion}

440

441

442

443

444

445

446

BEETLE ASSEMBLAGES IN BAMBOO VS. TERRA FIRME - Our results support the prediction that beetle community structure in bamboo forest differs from that of terra firme in terms of species richness, abundance, and composition. We found a greater number of beetle species (17.5\%) and individuals (43.8\%) in terra firme compared to bamboo forest, but nonetheless found high beetle richness (120 species) and abundance in bamboo forest. Though relative abundance distributions were similar between bamboo and terra firme, each community was characterized by a distinct set of dominant species and terra firme had a greater number of rare species. In analogous study systems comprised of two naturally-occurring, contrasting, and adjacent habitat types, most often in the form of forest and savanna, researchers have reported distinct beetle communities for each habitat (Kotze and Samways 2001; Spector and Ayzama 2003; Yu et al. 2007).

Our most striking results were the large number of beetle species found in bamboo, and that many species were only collected in bamboo forest and not in terra firme. Of the 120 beetle species we captured in the bamboo forest approximately $40 \%$ (48 species) were only collected in bamboo. Although further collecting might have yielded some of these species in terra firme, our results support the idea that bamboo is a rich habitat that contains a beetle community distinct from that of the adjacent terra firme. It is likely that some beetle species have evolved to specialize on bamboo forests as has been shown for other organisms (Kratter 1997; Davidson 2006; Kondo and Gullen 2004; Lebbin et al. 2007). 
461 Each beetle family exhibited different patterns of richness, abundance and composition within bamboo and terra firme. Because beetles from the Scarabaeidae constituted the majority of species in our collection (48\%), and the majority of individuals (83\%), diversity patterns of the scarabs were the most influential on the overall results. Out of the 24 most abundant species that best characterized either bamboo or terra firme, the greatest number of species (19) were scarab beetles (Table 3). All families except Histeridae were more species-rich in terra firme. All families except Carabidae (equally abundant in both forest types) were more abundant in terra firme.

We found significant differences in beetle community structure comparing bamboo and terra firme only for Scarabaeidae and Curculionidae. For Carabidae, it is possible that a low number of individuals (103) compared to the number of species (25), in addition to the high number of singleton and doubleton species in the carabid dataset (20), yielded nonsignificant results in terms of community structure between habitats. Data for the Carabidae family suggests that there are differences in beetle assemblages from bamboo and terra firme as there was a large turnover in species between bamboo and terra firme.

We collected many beetle species from every family that were found only in bamboo forest. Fifty-four percent of the carabid beetle species that we collected in bamboo were only from bamboo, followed by 59\% for the Curculionidae, $38 \%$ for the Histeridae, and $30 \%$ for the Scarabaeidae. In addition, we found the greatest number of singletons and doubletons in the Carabidae and Curculionidae which may be influencing the high degree of observed habitat affinity compared to the more abundant families of Histeridae and Scarabaeidae. Carabid and curculionid beetles may also be more sensitive to forest type. Additional, and more targeted sampling is necessary to elucidate habitat affinities for some beetle groups.

A number of studies have shown that invertebrate species richness is correlated with plant species richness (Siemann et al. 1998; Beals 2006; Schaffers et al. 2008). The high plant diversity of terra firme leads one to initially assume that terra firme habitat has more food resources than that of the neighboring bamboo forest, which may increase the number of herbivorous insects and other animals. The higher levels of plant-herbivore diversity could in turn increase animal diversity in higher trophic levels (Hunter and Price 1993; Brose 2003). Perhaps the fact that terra firme forest has more than double the number of tree species compared to adjacent bamboo-dominated forests (Griscom et al. 2007) accounts at least in part, for why we found more beetle species and individuals in terra firme (especially for Carabidae and Curculionidae). However, our results show that overall beetle species richness from terra firme is only $17.5 \%$ greater than that of bamboo forest - a proportional difference that, according to the hypothesis above, is smaller than would be expected based on tree diversity patterns. Though we did not inventory tree species in our sample sites, our results suggest that factors other than plant diversity are contributing to the relatively high diversity of beetles in bamboo forests.

For beetles in the families, Carabidae and Curculionidae, which are not often associated with dung and carrion, mechanistic hypotheses are more difficult. However, of our four target beetle families, these two families may be most strongly responding to the higher diversity of trees in the terra firme compared to bamboo forest. The majority of Neotropical carabid diversity occurs 
506 in the canopy of trees and the higher tree diversity of the terra firme may help explain the greater 507 diversity of carabid beetles collected in this forest type. In addition, many curculionid beetles are 508 plant, seed, or humus eaters, and thus may also be responding to the higher tree diversity of the 509 terra firme. Although we collected a greater number of species of these two families in the terra

510 firme, there was nonetheless high turnover in species composition between bamboo and terra 511 firme.

512

513 SEASONALITY AND FOREST TYPE - Seasonality alone is playing a role in structuring beetle 514 communities, though the effects are mixed for different beetle families. Overall, we found more species in the wet season and more individuals in the dry season. Differences in beetle community structure between bamboo and terra firme were more pronounced in the wet season. Additionally, terra firme exhibited greater seasonal variation in the number of individuals captured and greater species turnover between seasons. Seasons in southwestern Peru are primarily defined by fluctuations in rainfall, and it is often assumed that increased rainfall will drive an increase in observed richness resulting from increased activity of most insect species (Wolda 1978; Novotny and Basset 1998).

We captured 35\% more species in the wet season compared to the dry season, though many of the additional wet season species were singletons (i.e., the long tail in the species abundance distribution in Figure 6b). Based on previous studies (Pearson and Derr 1986; Devries et al.1999; Richards and Windsor 2007), we also expected to observe higher abundances in the wet season versus the dry season. Interestingly, we captured $10 \%$ more individuals in the dry season compared to the wet season. However, it is important to acknowledge that the observed pattern of higher beetle abundance in the dry season is being driven primarily by scarab and histerid beetles - the most abundant families in our study. For the family Carabidae, $84 \%$ of all individuals were captured in the wet season. The abundance of curculionid beetles was approximately equal across dry and wet seasons.

While examining the effects of both seasonality and forest type on beetle community structure, our results, along with those from recent studies (Lucky et al. 2002; Grimbacher and Stork 2009), illustrate that temporal patterns of insects may be more complex than originally assumed. Overall, we found that season had a slightly stronger influence than forest type on beetle community structure when simultaneously analyzing the effects of habitat and season. However, when comparing beetle community structure in bamboo and terra firme separately for the dry and wet seasons, we observed that community structure was more highly defined in the wet season compared to the dry season.

In addition, there was more variation in the number of individuals captured, and greater species turnover, between the dry and wet seasons in terra firme compared to bamboo forest. Interestingly, while we found a larger difference in the number of individuals collected between dry and wet seasons in the terra firme, there was not a clear directional pattern. Thus, we collected a greater number of individuals at some sites in the wet season and a greater number of individuals at other sites in the dry season. In contrast, species richness was clearly higher in the wet versus the dry season for terra firme compared to bamboo forest (Figs. 9a and b). It is possible that bamboo forest is a more "predictable" habitat than terra firme in terms of food resources. Because terra firme has a much higher diversity of plants than bamboo forest, greater 
552 fluctuations in food resources from varying flowering and fruiting phenologies may occur

553 throughout the year. Populations of beetle species that rely directly or indirectly on plant fruiting

554 phenologies may be affected by this variation in terra firme. The potentially higher variation in

555 beetle activity may explain why we observed more fluctuation in the number of individuals

556 captured, and greater species turnover, between dry and wet seasons in terra firme. In contrast,

557 bamboo plants from the genus Guadua do not experience the same annual phenological

558 fluctuations compared to other tree species because they flower and set seed approximately every

55930 years (Griscom et al. 2007).

560

561

Our results show that many beetle species are sensitive to seasonality and forest type. While a

562

563

564

565

566

567

568

569

570

571

572

573

574

575

576

577

578

579

580

581

582

583

584

585

586

587

588

589

590

591

592

593

594

595

596 handful of beetle species were equally abundant in bamboo and terra firme, across wet and dry seasons, many were not. Other species, such as Enema pan, exhibited a strong preference for one forest type in only one season (Online Resource 1). After conducting additional investigations of E. pan, we discovered that this species lives in close association with the bamboo plants (Jacobs et al. 2012). These results are important in that this species is possibly impacting bamboo plants through feeding and nesting damage, and because of their large size $(\sim 100 \mathrm{~mm})$, is potentially contributing considerably to the biomass of bamboo forest fauna (Fig. 11). In addition to E. pan, we found eight species of beetles that were captured in much greater numbers in the bamboo forest versus terra firme, suggesting that these species may also be associated with bamboo forest habitat (Online Resource 1). However, their biology is unknown. Bamboo-associated organisms are being discovered with increasing frequency (Jacobs \& von May 2012) and more in-depth field work, throughout the dry and wet seasons, is needed to determine if and why particular insect species are associated with specific forest types. Understanding insect diversity patterns in Guadua bamboo forests is particularly important because insects are the food source for so many other animals, and this is especially true for the 19 known species of insectivorous, Guaduaspecialist birds (Kratter 1997; Socolar et al. 2013).

\section{Conclusions}

Guadua bamboo forests are strikingly unique habitats because they occur as mono-dominant forest islands surrounded by hyper-diverse rainforest — providing an uncommon, spatially and biologically distinct habitat. Results from our study clearly show that bamboo forests in Peru maintain different communities of beetles compared to those of adjacent terra firme. Out of the total number of species that we collected in bamboo forest, $40 \%$ were collected only in bamboo forest. In addition, our results suggest that the species richness of beetles in terra firme is not considerably higher $(17 \%)$ than that of bamboo forest - a surprising result given the substantially higher tree diversity in terra firme. Historically, bamboo forests in southwestern Amazonia have been regarded as species-poor, weedy habitats because of their relatively low plant diversity. It is encouraging to see that more research efforts are focusing on this important component of western Amazonian ecosystems. Bamboo-associated animal communities require more exploration and study, and must be included in regional conservation plans seeking to protect entire animal communities in southwestern Amazonia. Furthermore, with increased interest in harvesting natural bamboo or creating bamboo plantations for alternative timber sources, naturally-occurring bamboo forests may be at risk. In southwestern Amazonia, Guadua bamboo forests are also threatened by deforestation due to agriculture, illegal mining, and illegal logging. 
597 Thus, more studies focusing on the ecology of native bamboo forests and their associated fauna 598 are of immediate and great importance.

599

600

601

602

603

604

605

606

607

608

609

610

611

612

613

614

615

616

617

618

619

620

621

622

623

624

625

626

627

628

629

630

631

632

633

634

635

636

637

638

639

640

641

\section{Acknowledgments}

We thank Jesus Ramos, Nigel Pitman, and the staff at Los Amigos Field Station for facilitating field work logistics. We thank Karina Ramirez for advice with permit applications. We thank Gerardo Lamas for support in the Entomology Department at the Museo de Historia Natural Universidad de San Marcos, Lima, Peru and the Entomology Department at the California Academy of Sciences. We thank Don Driscoll for help with preliminary sampling and initial study design. We also thank Trond Larsen, Terry Erwin, Michael Caterino, Kipling Will, Brett Ratcliffe, and Charles O'Brien for help with identifying beetle species. We additionally thank Daniel Lebbin and Jan Olivier for help with describing, selecting and mapping bamboo forest patches at Los Amigos Field Station, and to Bruce Nelson for providing information on Guadua bamboo life history dynamics. We thank Terry Erwin and Crystal Ernst for providing constructive comments and suggestions.

\section{References}

Anderson RS (2008) A review of the Neotropical genus Eucalandra Faust, 1899 (Coleoptera; Curculionidae: Dryophthorinae). Zootaxa 1791:57-67

Baker SC, Barmuta LA (2006) Evaluating spatial autocorrelation and depletion in pitfall-trap studies of environmental gradients. J of Insect Cons 10:269-276

Barbosa O, Marquet, PA (2002) Effects of forest fragmentation on the beetle assemblage at the relict forest of Fray Jorge, Chile. Oecologia 132:296-306

Beals ML (2006) Understanding community structure: a data-driven multivariate approach. Oecologia 150:484-495

Blaum N, Seymour C, Rossmianith E, Schwager M, Jeltsch F (2009) Changes in arthropod diversity along a land use driven gradient of shrub cover in savanna rangelands: identification of suitable indictors. Biodiversity Conserv 18:1187-1199

Brose U (2003) Bottom-up control of carabid beetle communities in early successional wetlands: mediated by vegetation structure of plant diversity? Oecologia 135:407-413

Clarke KR (1993) Non-parametric multivariate analyses of changes in community structure. Aus. J. Ecol. 18:117-143

Clarke KR, Gorley RN (2006) PRIMER v6: User Manual/Tutorial. PRIMER-E, Plymouth, UK 
642 Clarke KR, Warwick RM (1994) Change in marine communities: an approach to statistical 643 analyses and interpretation. Primer-E. Natural Environment Research Council, Plymouth, UK

644

645

646

647

648

649

650

651

652

653

654

655

656

657

658

659

660

661

662

663

664

665

666

667

668

669

670

671

672

673

674

675

676

677

678

679

680

681

682

683

684

685

686
Crump ML (1971) Quantitative analysis of the ecological distribution of a tropical herpetofauna.

Occasional Papers of the Museum of Natural History The University of Kansas 3:1-62

Coddington JA, Agnarsson I, Miller JA, Kuntner M, Hormiga G (2009) Undersampling bias: the null hypothesis for singleton species in tropical arthropod surveys. J of Anim. Ecol. 78:573-584

Colwell RK (2005) EstimateS: Statistical Estimation of Species Richness and Shared Species

from Samples, Version $7.5 \mathrm{http}$ ://viceroy.eeb.uconn.edu/estimates, accessed 3/15/09

Davidson DW, Arias JA, Mann (2006a) An experimental study of bamboo ants in western Amazonia. Insect Soc 53:108-114

Davidson DW, Castro-Delgado SR, Arias JA, Mann J (2006b) Unveiling a ghost of Amazonian rain forests: Camponotus mirabilis, engineer of Guadua bamboo. Biotropica 38(5): 653-666.

Delsinne T, Leponce M, Laurence T, Braet Y, Roisin Y (2008) Rainfall influences ant sampling in dry forests. Biotropica 40(5): 590-596

Dennis P, Young MR, Gordon IJ (1998) Distribution and abundance of small insects and arachnids in relation to structural heterogeneity of grazed, indigenous grasslands. Ecol Entomol 23:253-264

Dennis P, Young MR, Howard CL, Gordon IJ (1997) The response of epigeal beetles (Col.: Carabidae, Staphylinidae) to varied grazing regimes on upland Nardus stricta grasslands. J Appl Ecol 24:433-443

Devries PJ, Walla TR, Greeney HF (1999) Species diversity in spatial and temporal dimensions of fruit-feeding butterflies from two Ecuadorian rainforests. Biol J Linn Soc 68:333-353

Didham RK (1997) The influence of edge effects and forest fragmentation on leaf litter invertebrates in central Amazonia. In: Laurance WF and Bierregaard Jr. RO (ed) Tropical Forest Remnants: Ecology, Management, and Conservation of Fragmented Communities. University of Chicago Press, Chicago pp 55-70

Driscoll DA (2005) Is the matrix a sea? Habitat specificity in a naturally fragmented landscape. Ecol Entomol 30:8-16

Dunnum JL, Salazar-Bravo J (2004) Dactylomys boliviensis. Mamm Spec 745:1-4

Emmons LH, Feer F (1990) Neotropical rainforest mammals: A field guide. University of Chicago Press, Chicago 
687 Erwin TL (1997) Natural history of the carabid beetles at the BIOLAT Biological Station, Rio 688 Manu, Pakitza, Peru, Supplement I. Additional records. In: Wilson DE, Sandoval A (ed) Manu: 689 The Biodiversity of Southeastern Peru. The Smithsonian Institution Press, Washington D.C. pp $690 \quad 359-368$

691

692 Foster RB, Carr JL, Forsyth AB (1994) The Tambopata-Candamo reserved zone of southeastern 693 Peru: a biological assessment. Rapid Assessment Program. Working Papers 6. Conservation 694 International, Washington D.C.

695

696

697

Gardner TA, Fitzherbert EB, Drewes RC, Howell KM, Caro T (2007) Spatial and temporal patterns of abundance and diversity of an east African leaf litter amphibian fauna. Biotropica

698

699

700

701

702

703

704

705

706

707

708

709

710

711

712

713

714

715

716

717

718

719

720

721

722

723

724

725

726

727

728

729 39(1):105-113

Grimbacher PS, Stork NE (2009) Seasonality of a diverse beetle assemblage inhabiting lowland tropical rain forest in Australia. Biotropica 41(3):328-337

Griscom BW, Ashton PMS (2003) Bamboo control of forest succession: Guadua sarcocarpa in Southeastern Peru. Forest Ecol Manag 175: 445-454

Griscom BW, Ashton PMS (2006) A self-perpetuating bamboo disturbance cycle in a neotropical forest. J Trop Ecol 22:587-597

Griscom BW, Daly DC, Ashton PMS (2007) Florisitics of bamboo-dominated stands in lowland terra-firma forests of southwestern Amazonia. J Torrey Bot Soc 134(1):108-125

Hunter MD, Price PW (1993) Playing chutes and ladders: heterogeneity and the relative roles of bottom-up and top-down forces in natural communities. Ecology 73:724-732

Jacobs JM, von May R (2012) Forest of Grass: discovering biodiversity in the Amazon's bamboo jungles. Natural History Magazine Jan: 22-29

Jacobs JM, von May R, Ratcliffe BC (2012) Observations on the life history of Enema pan (Fabricius) (Coleoptera: Scarabaeidae: Dynastinae) and its association with bamboo plants (Guadua Kunth: Poaceae: Bambusoideae) in southwestern Amazonia. The Coleops Bull 66(3): 253-260

Janzen DH (1973) Sweep samples of tropical foliage insects: Effects of seasons, vegetation types, elevation, time of day, and insularity. Ecology 54:687-708

Judziewickz EJ, Clark LG, Londoño X, Stern MJ (1999) American Bamboos. Smithsonian Institution Press, Washington D.C.

Kratter AW (1997) Bamboo specialization by Amazonian birds. Biotropica 29(1):100-110

730 
731 Kondo T, Gullan PJ (2004) A new species of ant-tended soft scale of the genus Cryptostigma

732 Ferris (Hemiptera: Coccidae) associated with bamboo in Peru. Systematics, Morphology, and

733 Physiology Nov - Dec: 717-723

734

735

736

737

738

739

740

741

742

743

744

745

746

747

748

749

750

751

752

753

754

755

756

757

758

759

760

761

762

763

764

765

766

767

768

769

770

771

772

773

774

775

Kotze DJ, Samways MJ (1999) Invertebrate conservation at the interface between the grassland matrix and natural Afromontane forest fragments. Biodivers Conserv 8:1339-1363

Kotze DJ, Samways MJ (2001) No general edge effects for invertebrates at Afromontane forest/grassland ecotones. Biodivers Conserv 10:443-466

Larsen TH, Lopera A, Forsyth A (2006) Extreme trophic and habitat specialization by Peruvian dung beetles. The Coleopts Bull 60(4): 315-324

Lawton JH (1983) Plant architecture and the diversity of phytophagous insects. Annu Rev Entomol 28:23-39

Lebbin DJ (2006) Notes on birds consuming Guadua bamboo seeds. Ornitol Neotropic 17:602612

Lebbin DJ (2007) Habitat specialization among Amazonian birds: why are there so many bamboo specialists? Dissertation, Cornell University

Lebbin DJ, Hosner PA, Anderson MJ, Valdez U, Tori WP (2007) First description of nest and eggs of the White-lined antbird (Percnostola lophotes), and breeding observations of poorly known birds inhabiting Guadua bamboo in southeastern Peru. Bol SAO Vol. XVII(2): 119-132

Ledesma KJ (2003) Small mammal communities of bamboo forests in the Peruvian Amazon. Master's Thesis, Florida Atlantic University

Longino JT, Coddington J, Colwell RK (2002) The ant fauna of a tropical rain forest: Estimating species richness three different ways. Ecology 83:689-702

Longino JT, Colwell RK (1997) Biodiversity assessment using structured inventory: capturing the ant fauna of a tropical rain forest. Ecological Applications 7(4):1263-1277

Louton J, Gelhaus J, Bouchard R (1996) The aquatic macrofauna of water-filled bamboo (Poaceae: Bambusoideae: Guadua) internodes in a Peruvian lowland tropical forest. Biotropica $28: 228-242$

Lucky A, Erwin TL, Witman JD (2002) Temporal and spatial diversity and distribution of arboreal Carabidae (Coleoptera) in a western Amazonian rain forest. Biotropica 34(3):376-386

Magurran AE (2004) Measuring Biological Diversity. Blackwell Publishing, UK

Nelson BW (1994) Natural forest disturbance and change in the Brazilian Amazon. Rem Sens Revs 10:105-125 
777

778

779

780

781

782

783

784

785

786

787

788

789

790

791

792

793

794

795

796

797

798

799

800

801

802

803

804

805

806

807

808

809

810

811

812

813

814

815

816

817

818

819

820

821

Nelson BW, Bianchini MC (2005) Complete life cycle of southwest Amazon bamboos (Guadua spp) detected with orbital optical sensors. Anais XII. Simpósio Brasileiro de Sensoriamento Remoto, INPE, Goiânia, Brasil pp 1629-1636

Novotny V, Basset Y (1998) Seasonality of sap-sucking insects (Auchenorrhyncha, Hemiptera) feeding on Ficus (Moraceae) in a lowland rain forest in New Guinea. Oecologia 115: 514-522

Olivier J (2007) Etude spatio-temporelle de la distribution de bambous dans le Sud-ouest amazonien (Sud-Pérou). Histoire, dynamique et futur d'une végétation « monodominante » en forêt tropicale humide. Dissertation, Université Paul Sabatier, Toulouse, France

Olivier J (2008) Gramíneas (Poaceae) bambusiformes del Río de Los Amigos, Madre de Dios, Perú. Rev Peru Biol 15(1):121-126

Olivier J, Otto T, Roddaz M, Antoine PO, Londoño X, Clark LG (2008) First macrofossil evidence of a pre-Holocene thorny bamboo cf. Guadua (Poaceae: Bambusoideae: Bambuseae: guaduinae) in south-western Amazonia (Madre de Dios-Peru). Rev Paleob and Palyno 15(3):1-7

Pearson DL, Derr JA (1986) Seasonal patterns of lowland forest floor arthropod abundance in southeastern Peru. Biotropica 18(3): 244-256

Pitman NCA (2008) An overview of the Los Amigos Watershed, Madre de Dios, southeastern Peru. Amazon Conservation Association.

http://cicra.acca.org.pe/espanol/paisaje_biodiversidad/los-amigos-overview9.pdf. Accessed 12 March 2009

Richards LA, Windsor DM (2007) Seasonal variation of arthropod abundance in gaps and the understory of a lowland moist forest in Panama. J Trop Ecol 23:169-176

Ruíz-Sánchez E (2011) Biogeography and divergence time estimates of woody bamboos: insights in the evolution of Neotropical bamboos. B Soc Bot Mex 88:67-75

Schaffers AP, Raemakers IP, Sýkora KV, Ter Braak CJF (2008) Arthropod assemblages are best predicted by plant species composition. Ecology 89(3):782-794

Schoereder JH, Galbiati C, Ribas CR, Sobrinho TG, Sperber CF, DeSouza O, Lopes-Andrade C (2004) Should we use proportional sampling for species-area studies? J Biogeogr 31: 1219-1226

Siemann E, Tilaman D, Haarstad J, Ritchie M (1998) Experimental tests of the dependence of arthropod diversity on plant diversity. The American Naturalist 152:738-750

Socolar SJ, Robinson SK, Terborgh J (2013) Bird diversity and occurrence of bamboo specialists in two bamboo die-offs in southeastern Peru. The Condor 115(2): 253-262 
822 Spector S, Aysama S (2003) Rapid turnover and edge effects in dung beetle assemblages

823 (Scarabaeidae) at a Bolivian neotropical forest-savanna ecotone. Biotropica 35(3):394-404

824

825

von May R, Medina-Müller M, Donnelly MA, Summers K (2008) The tadpole of the bamboo-

826

827

828 von May R, Medina-Müller M, Donnelly MA, Summers K (2009a) Breeding-site selection by 829 poison frogs (Ranitomeya biolat) in Amazonian bamboo forests: an experimental approach. Can 830 J Zoolog 87(5):453-464

831

832 von May R, Siu-Ting K, Jacobs JM, Medina-Müller M, Gagliardi G, Rodríguez LO, Donnelly 833 MA (2009b) Species diversity and conservation status of amphibians in Madre de Dios, Perú.

834 Herpetol Cons and Biol 4:14-29

835

836 von May R, Jacobs JM, Santa Cruz R, Valdivia J, Huamán J, Donnelly MA (2010) Amphibian

837 community structure as a function of forest type in Amazonian Peru. J Trop Ecol 26(5): 509-519

838

839

840

841

842 Ward DF, New TR, Yen AL (2001) Effects of pitfall trap spacing on the abundance, richness and 843

844

845

846

847

848

849

850

Ward DF, Larivière M-C (2004) Terrestrial invertebrate surveys and rapid biodiversity assessment in New Zealand: Lessons from Australia. NZ J Ecol 28(1):151-159

composition of invertebrate catches. J Insect Conserv 5(1):47-53

Wolda H (1978) Seasonal fluctuations in rainfall, food and abundance of tropical insects. J Anim Ecol 47(2):369-381

Work TT, Buddle CM, Korinus LM, Spence JR (2002) Pitfall trap size and capture of three taxa of litter-dwelling arthropods: implications for biodiversity studies. Environ Entomol 31(3):438448

851

852 Yu DX, Luo TH, Zhou HZ, Yang J (2007) Distribution of Carabid beetles (Coleoptera:

853 Carabidae) across a forest-grassland ecotone in southwestern China. Community Ecosys Ecol 36: $854 \quad 348-355$ 
855

856

857
858

861

862

863

864

865

866

867

868

869

870

871

872

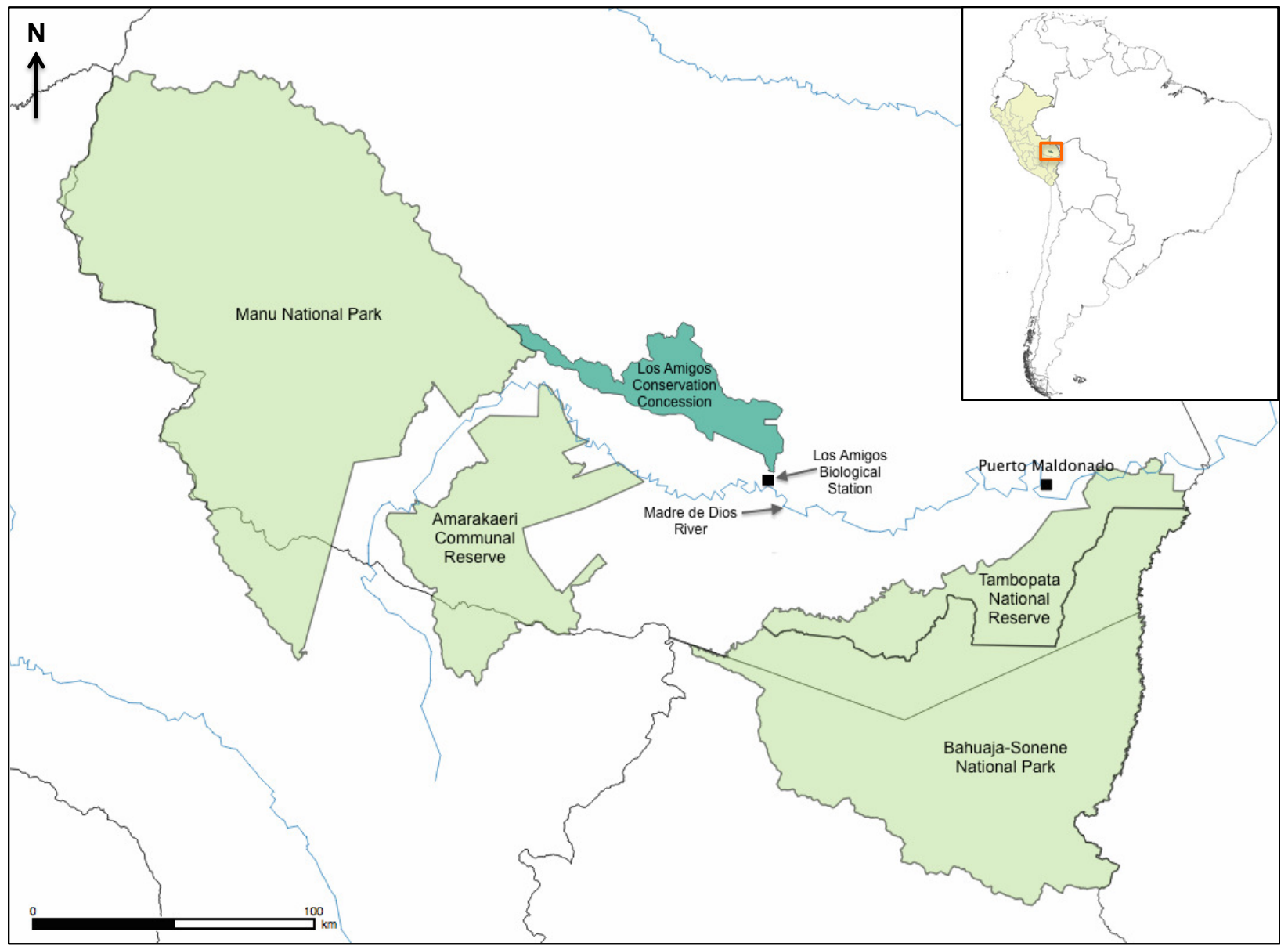

Fig 1. Map of southeastern Peru showing the location of the study area and other protected areas. All collecting took place near Los Amigos Biological Station, which is found on the southernmost border of the Los Amigos Conservation Concession. The other natural protected areas are Manu National Park, Amarakaeri Communal Reserve, Tambopata National Reserve, and Bahuaja-Sonene National Park. The inset shows the location of the study area in South America (Peru highlighted in yellow; area shown in detail in orange polygon). Map by Rudolf von May, made with QGIS (https:/qgis.org/en/site/). 
873

874

875

876

877

878

879

880

881

882

883

884

885

886

887

888

889

890

891

892

893

894

895

896

897

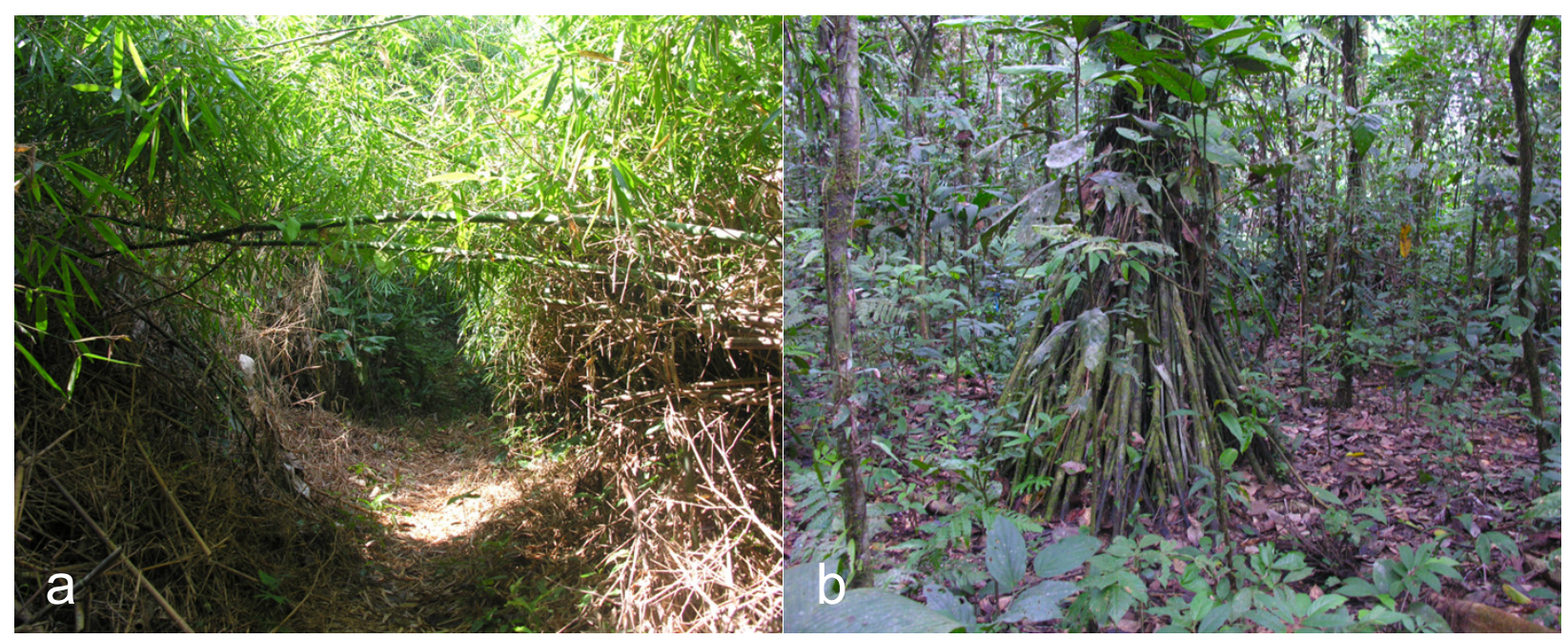

Fig. 2. Views of a dense patch of Guadua weberbauri bamboo habitat with trail cut through patch (A) and of the terra firme habitat (B) studied at Los Amigos Biological Station, Peru. Photographs by Jennifer M. Jacobs. 


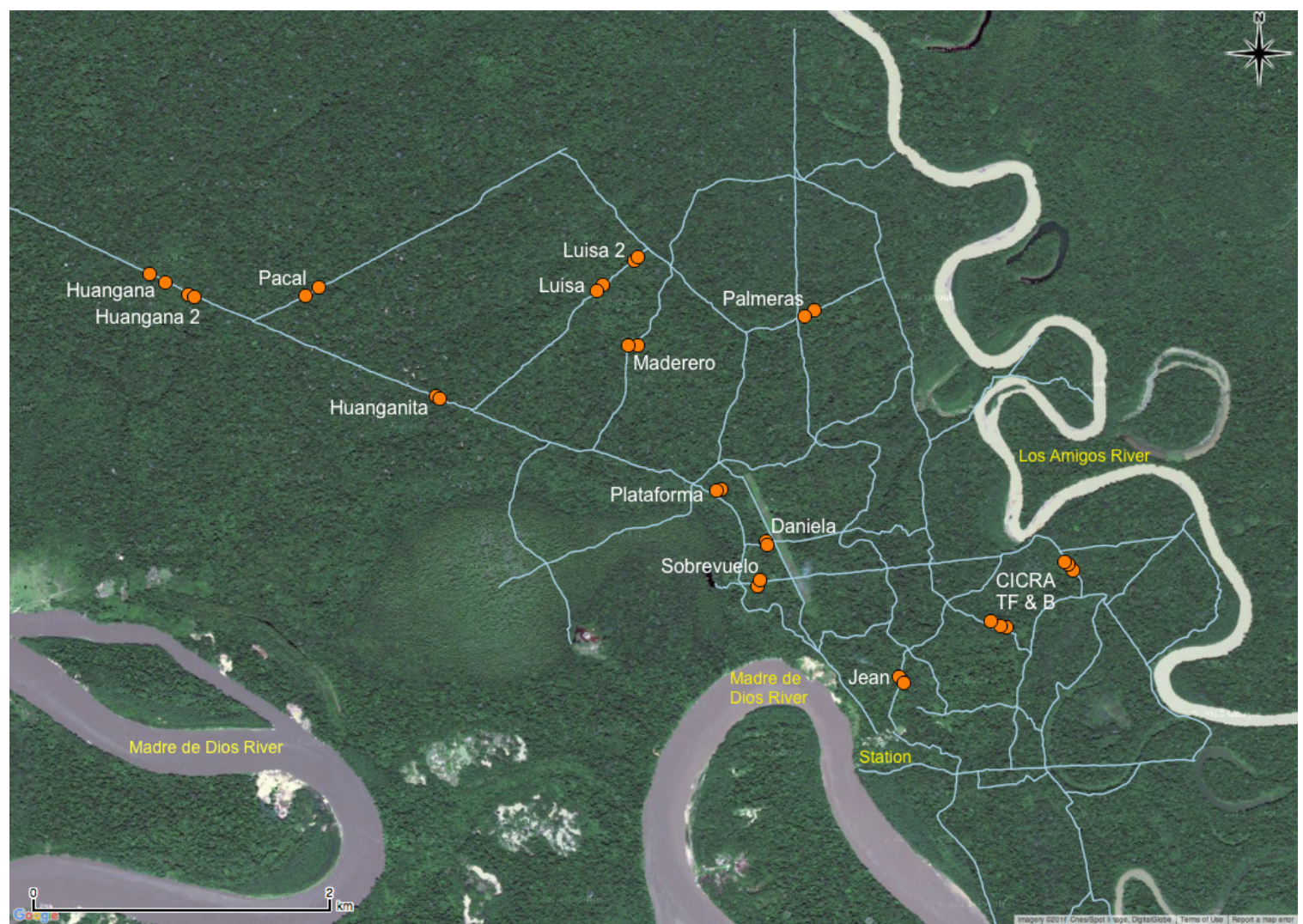

Fig. 3. Map of the study area showing the general location of trap arrays (orange circles). The

900 name of each trap array is noted in white and the trail system of Los Amigos Biological Station 901 is shown in light blue. Scale bar $=2 \mathrm{~km}$. Source of background and trail system layers: Google 902 Satellite and Amazon Conservation Association.

903

904

905

906

907

908

909

910

911

912

913

914

915

916

917

918

919

920

921 


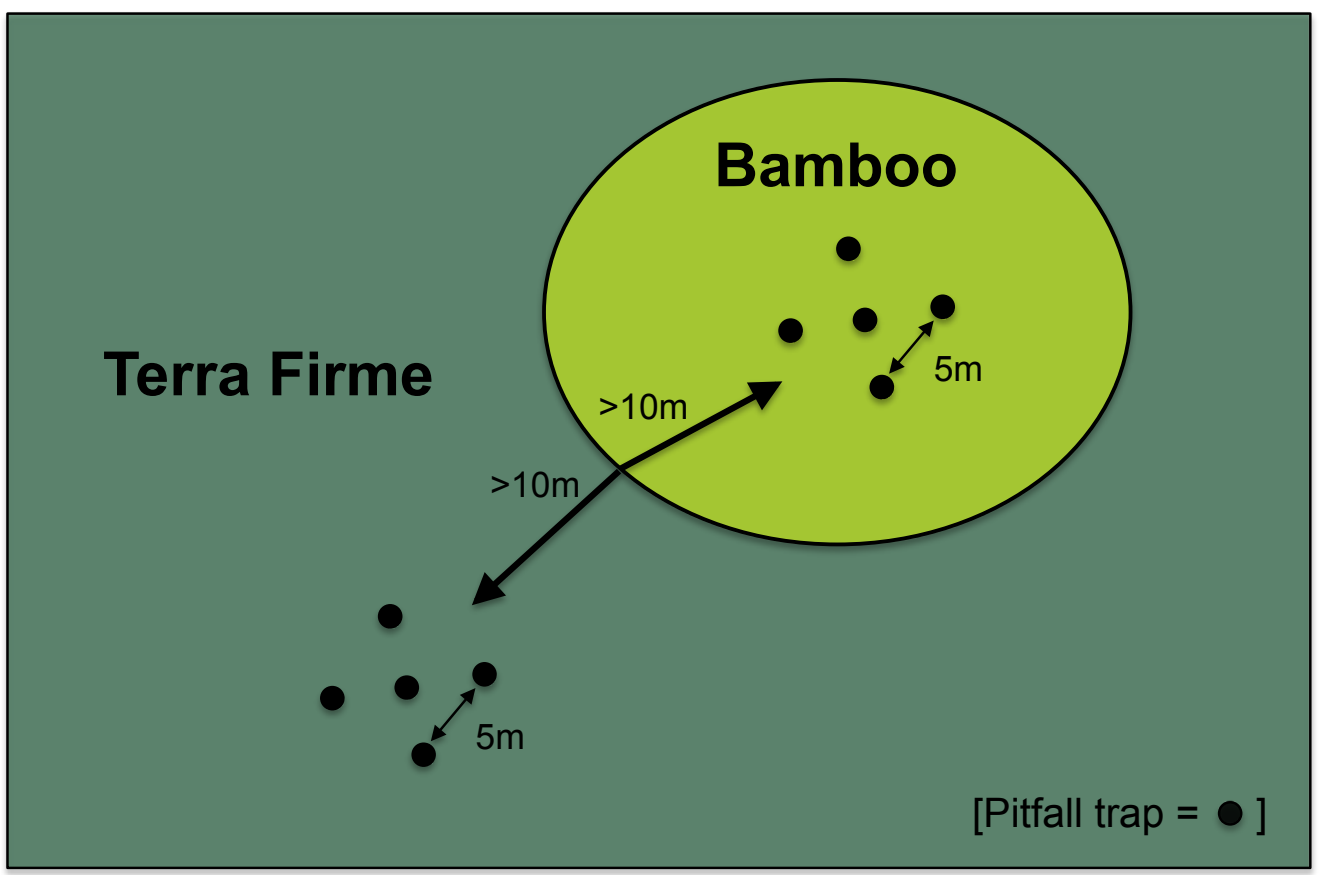

Fig. 4 Sampling scheme of paired sites in bamboo and terra firme forest. Each pair of forest 924 types received the same number of pitfall traps in the same array. Pitfall trap arrays were always greater than 10 meters from the edge of a forest type and individual traps were always five meters apart. 

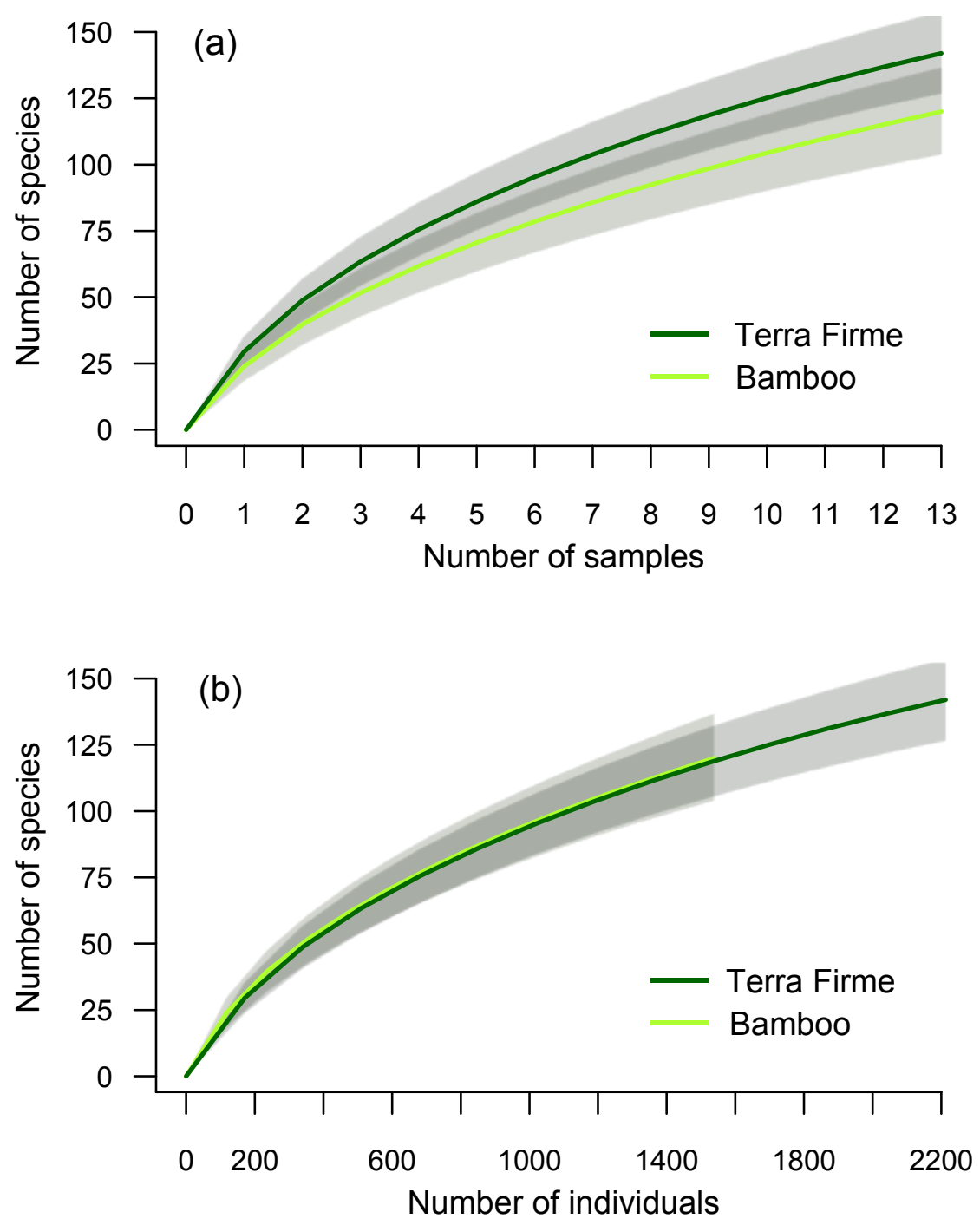

931

932 Fig. 5 Species accumulation curves. (a) The number of species collected in bamboo and 933 terra firme forests as a function of sampling effort and (b) the number of species collected in 934 bamboo and terra firme forests as a function of number of individuals collected (shaded areas 935 indicate $95 \%$ confidence intervals). 

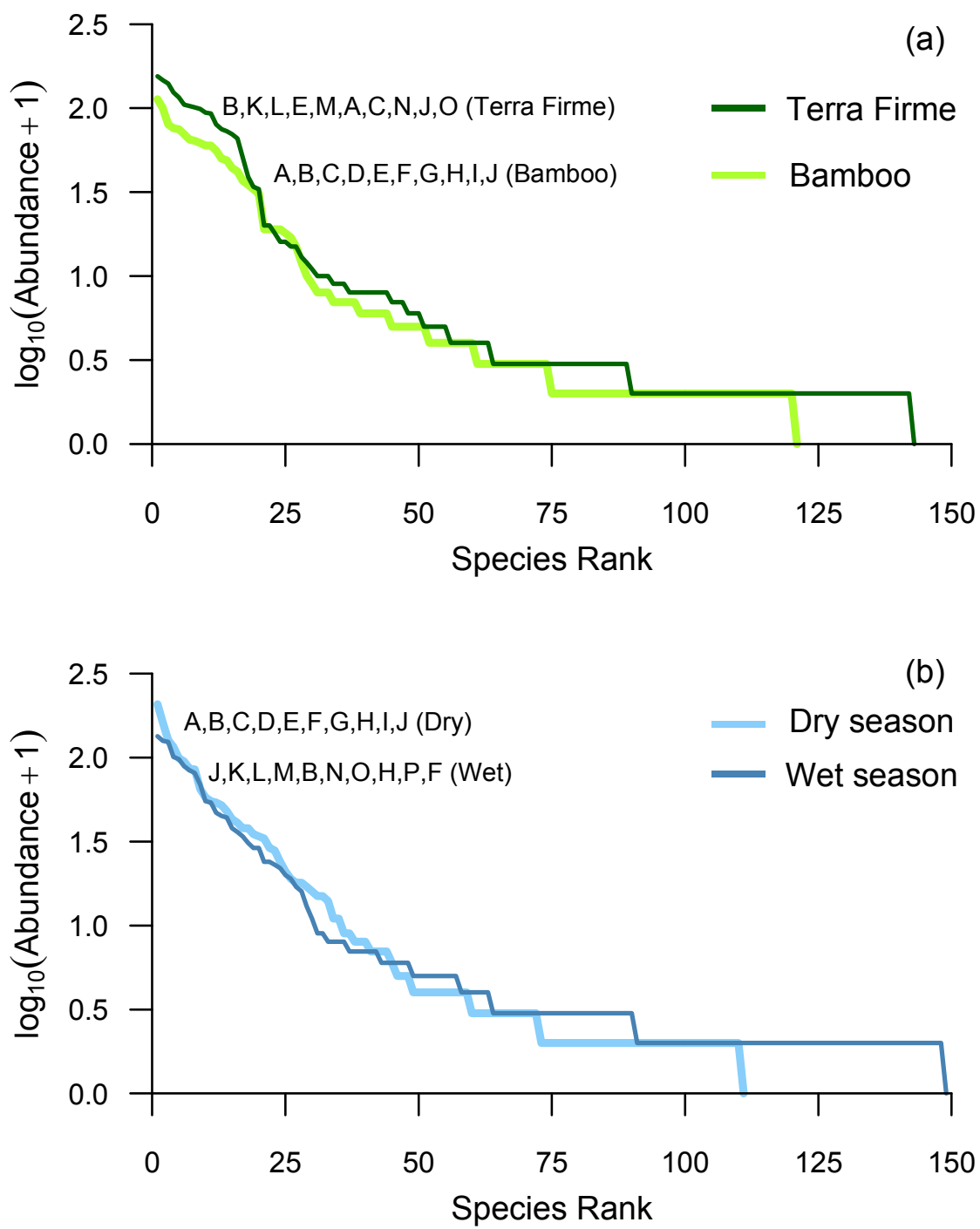

946

947

948

949

950

951

952

953

954
Fig. 6 Whitaker plots comparing rank abundances between (a) forest types and (b) seasons. Species are ranked according to their abundances. Each letter represents one species, and the ten most abundant species are ordered. For each plot, one letter represents the same species, and a new letter is assigned for every new species. However, the letters are not constant for both plots in that species D in plot (a) may not be species D in plot (b). The lettered order illustrates that the ten most abundant species are not the same for bamboo and terra firme, and dry and wet seasons. 


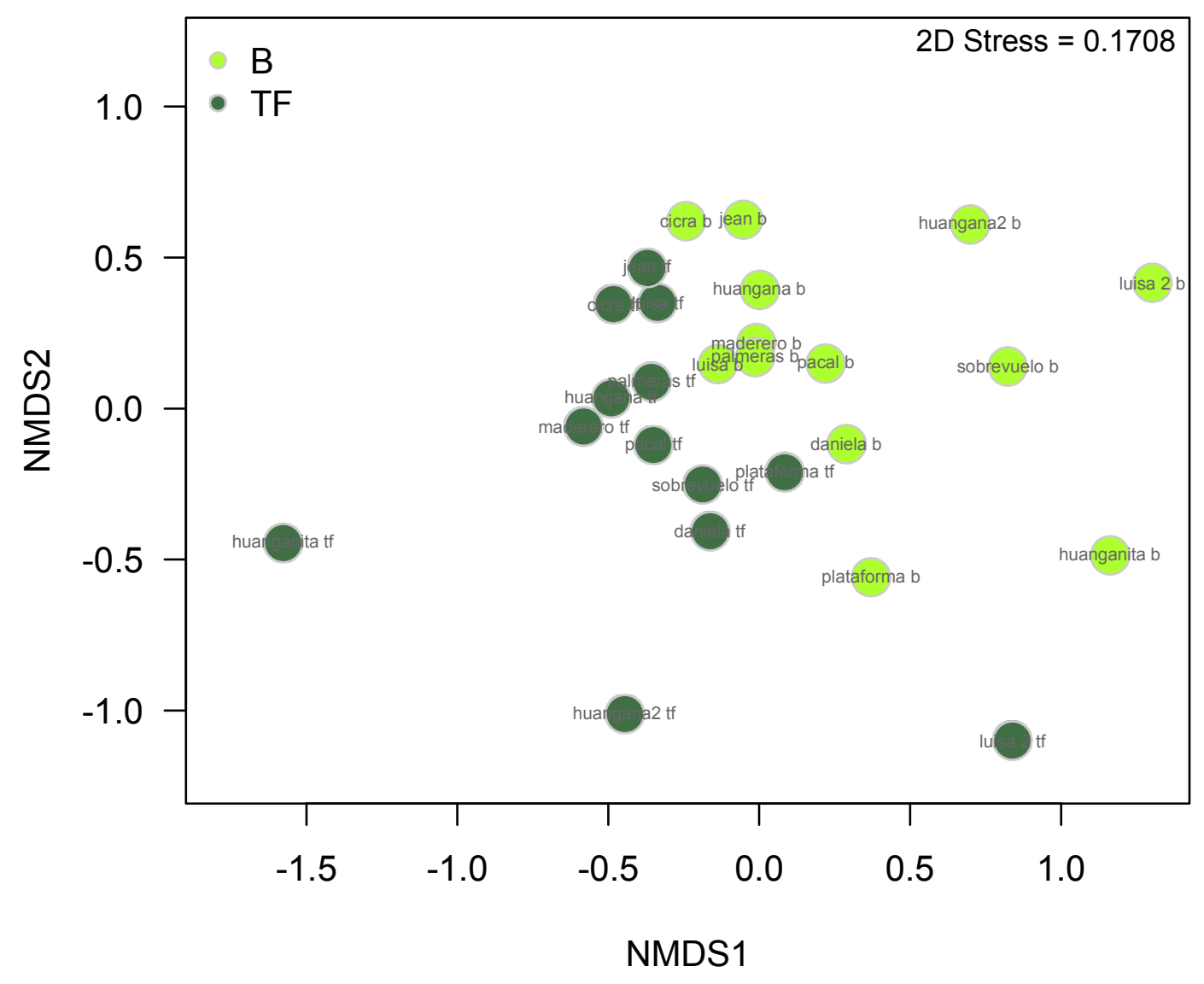

956 Fig. 7 nMDS plot illustrating beetle community structure between bamboo and terra firme forest 957 with data from all families and seasons pooled. The plot exhibits distinct communities of beetles 958 in the two forest types with some degree of overlap between assemblages. Distance measure $=$ 959 Bray-Curtis. Legend: $\mathrm{B}=$ Bamboo forest, $\mathrm{TF}=$ Terra firme forest.

960

961

962 


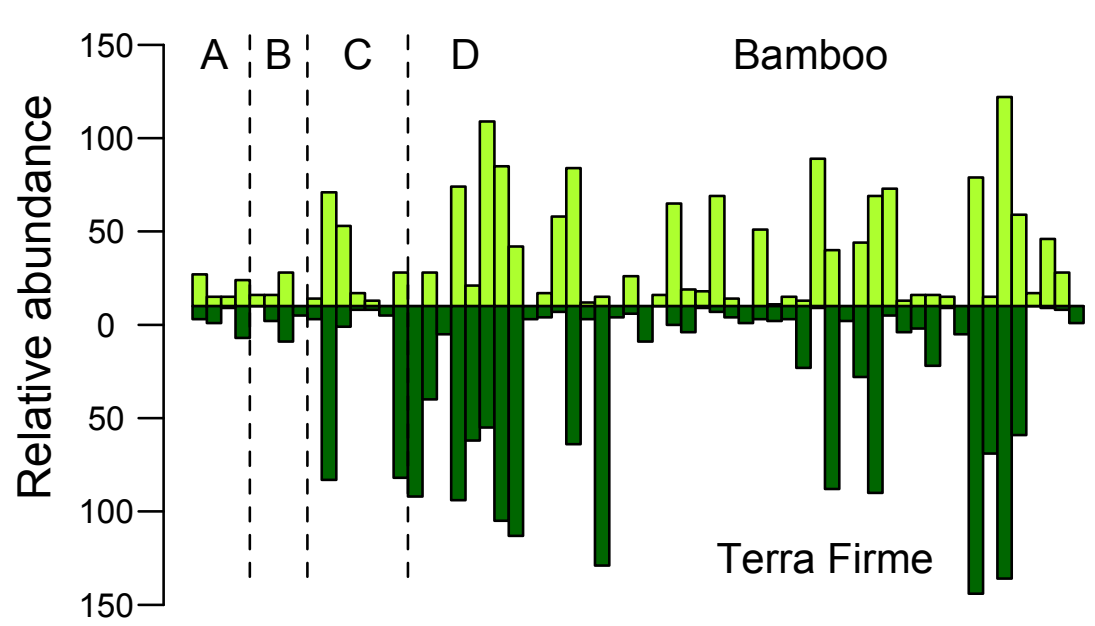

(a)

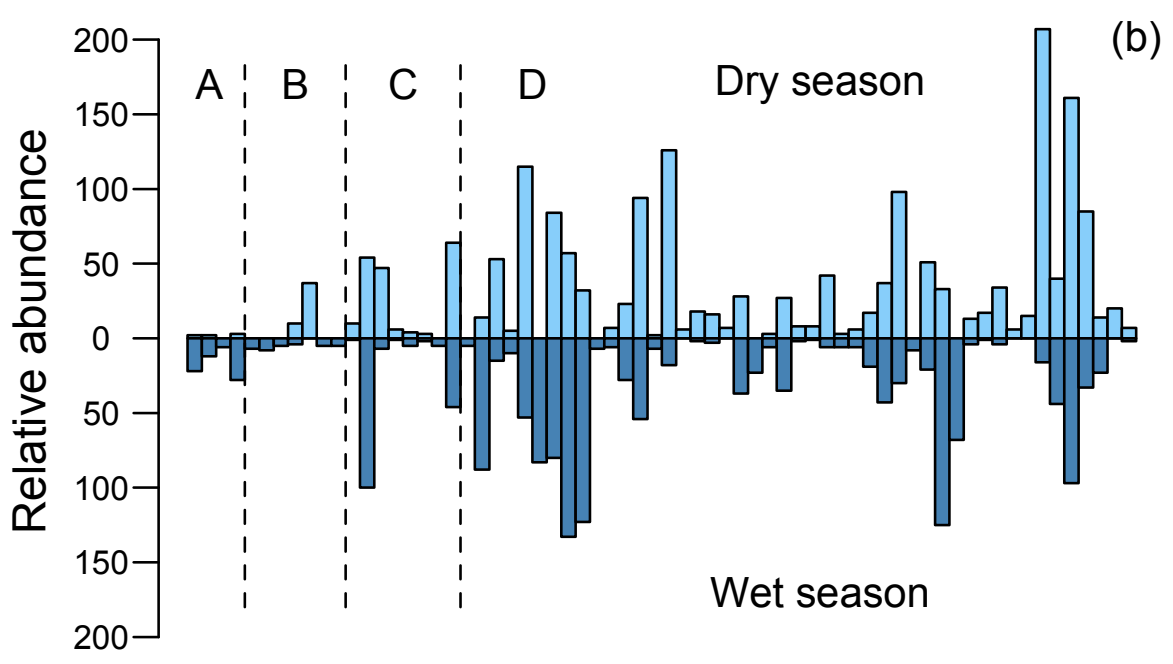

963

964

965

966

967

968

969
Fig. 8 Matched rank/occurrence plots for (a) bamboo and terra firme forest and (b) dry and wet seasons. Each pair of positive (dark) and negative (hatched) bars represents the relative abundance of one species in each forest type or each season. The letter "A" column represents beetles from the family Carabidae, "B" represents Curculionidae, "C" represents Histeridae and "D” represents Scarabaeidae 

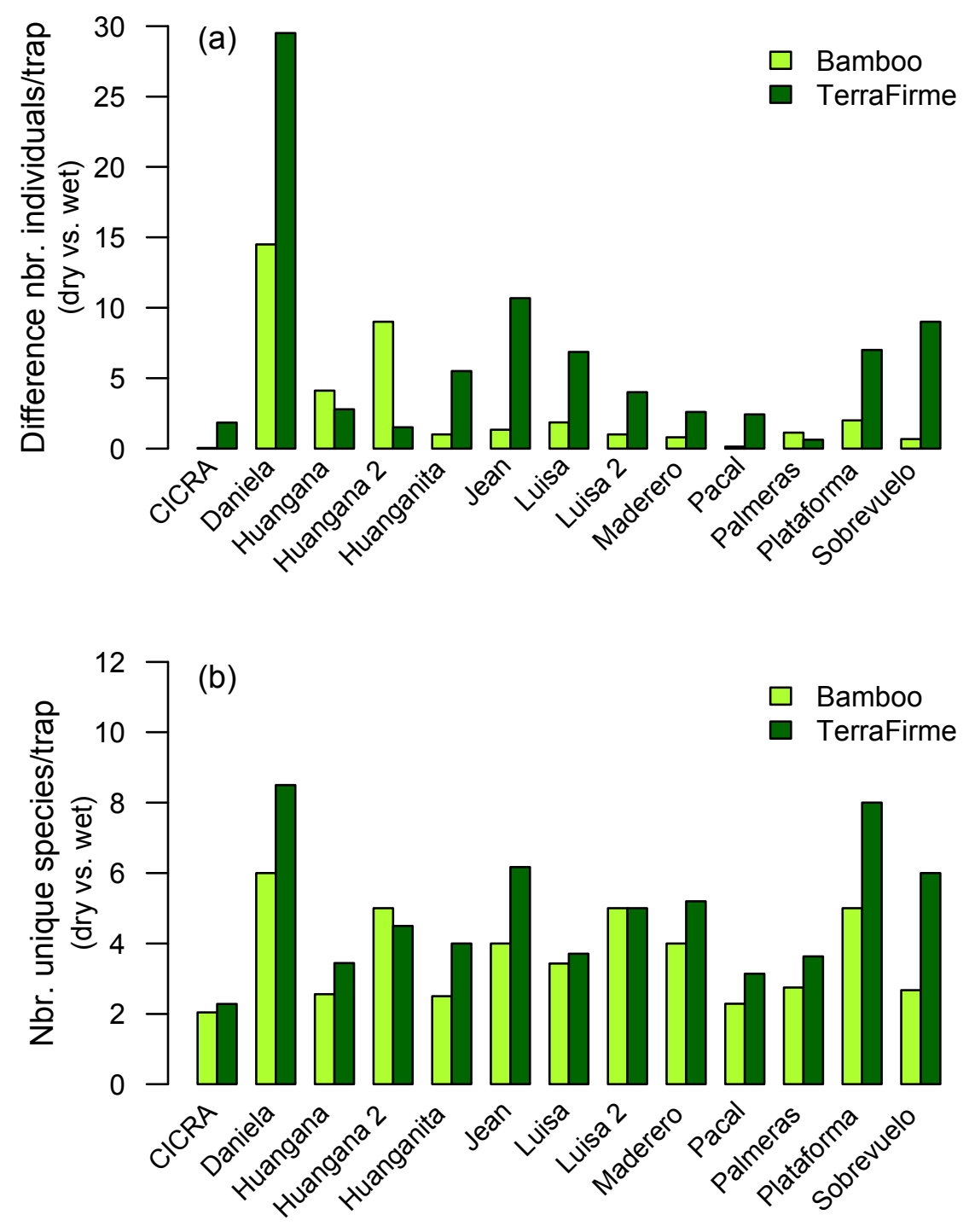

970

971

972

973

974

975

976

977

978

979

980

981
Fig. 9 Plots expressing variation in (a) numbers of individuals/trap and (b) numbers of unique species/trap captured between dry and wet seasons, for bamboo forest compared to terra firme forest, at all sites. (a) Each bar represents the difference in number of individuals/trap captured between the dry and wet season in one forest type. (b) Each bar represents the number of unique (not shared) species captured/trap in the dry and wet season, in one forest type. In both (a) and (b), the pattern to observe is the difference between the paired white and black bars, not that some bars are higher than others. Overall, there was more variation in the numbers of individuals captured and greater species turnover between dry and wet seasons in the terra firme forest compared to bamboo forest 
982
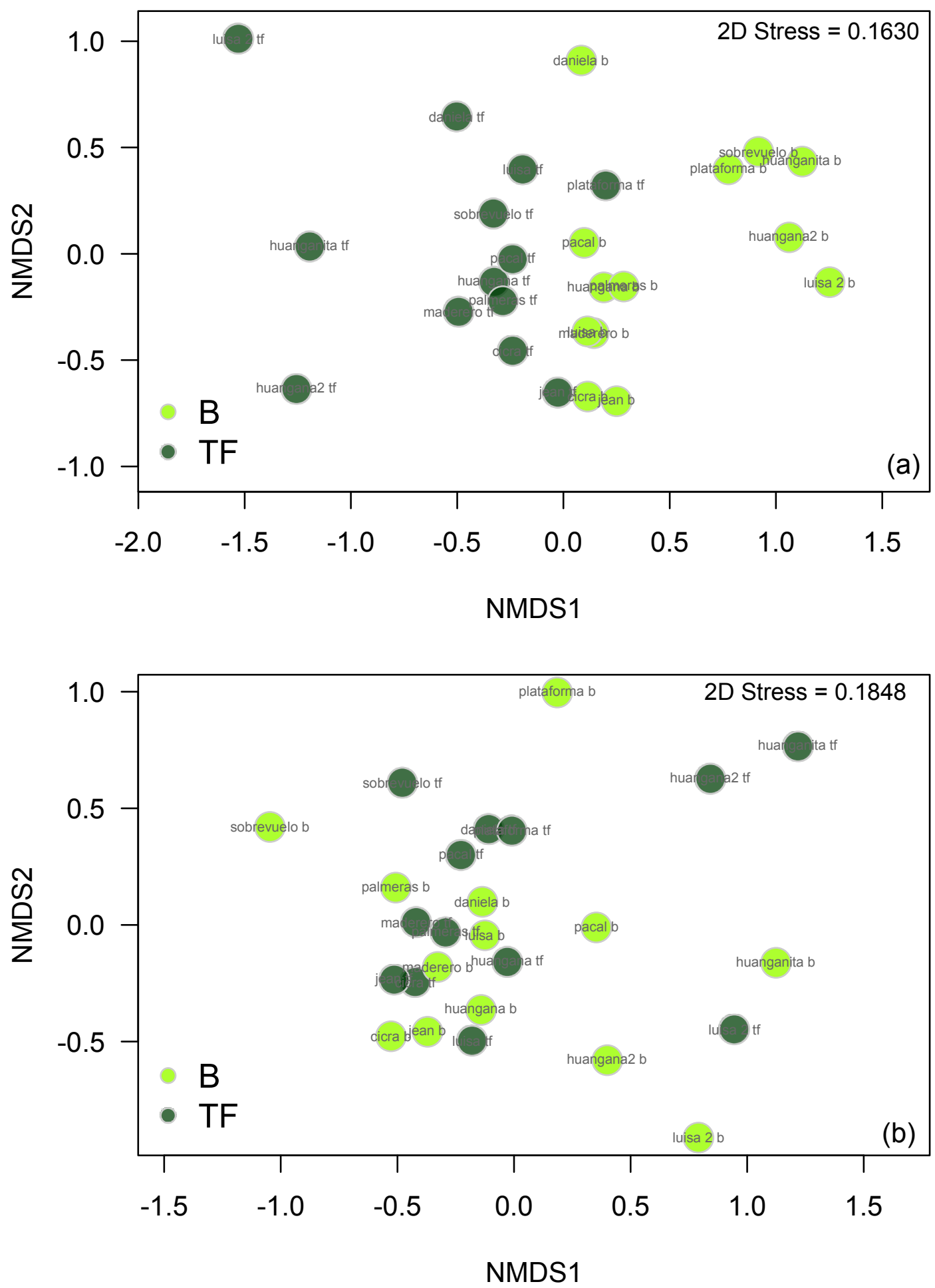

983

984 Fig. 10 nMDS plots comparing beetle community structure between bamboo and terra firme 985 forest in (a) the wet season only and (b) the dry season only. There is a greater distinction in 986 beetle community structure between bamboo and terra firme forest in the wet season compared 987 to the dry season. 
988

989

990

991

992

993

994

995

996

997

998

999

1000

1001

1002

1003

1004

1005

1006

1007

1008

1009

1010

1011

1012

1013

1014

1015

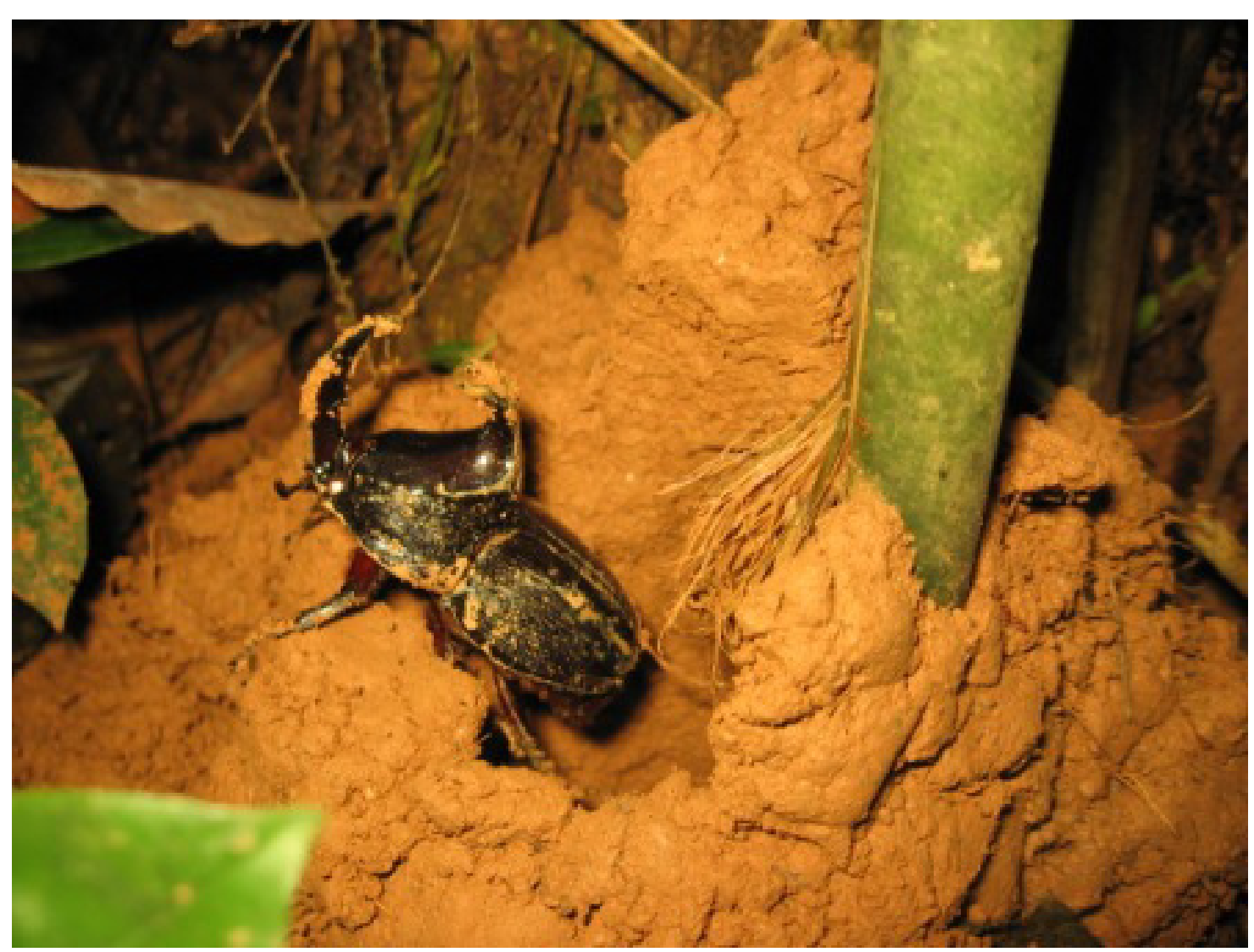

Fig. 11 Individual of male Enema pan perching outside of his mound entrance at the base of a Guadua weberbaueri stem. Enema pan beetles construct these mounds connecting underground to approximately 1-meter long tunnels. When the mound is closed during the day, they stay hidden in their tunnels and feed on bamboo sap through the bark that they have shredded at the base of the bamboo stem. They open their mounds at night and perch at the entrance of their mound, presumably looking for mates or guarding the entrances to the mound. Photograph by Jennifer M. Jacobs. 
1017 Table 1. The number of species of beetle in each family, and in all families combined, collected 1018 in only bamboo forest, only terra firme forest, in both habitats, only in the dry season, only in the 1019 wet season, and both seasons. The 7th column lists the total number of species collected per 1020 family.

1021

\begin{tabular}{lccccccc}
\hline Richness & $\begin{array}{c}\text { Bamboo } \\
\text { only }\end{array}$ & $\begin{array}{c}\text { Terra } \\
\text { Firme } \\
\text { only }\end{array}$ & $\begin{array}{c}\text { Both } \\
\text { habitats }\end{array}$ & $\begin{array}{c}\text { Dry } \\
\text { only }\end{array}$ & $\begin{array}{c}\text { Wet } \\
\text { only }\end{array}$ & $\begin{array}{c}\text { Both } \\
\text { seasons }\end{array}$ & $\begin{array}{c}\text { Total no. } \\
\text { species }\end{array}$ \\
\hline Carabidae & 7 & 12 & 6 & 7 & 15 & 4 & 25 \\
Curculionidae & 16 & 25 & 11 & 13 & 31 & 8 & 52 \\
Histeridae & 6 & 6 & 10 & 7 & 5 & 10 & 22 \\
Scarabaeidae & 19 & 26 & 45 & 14 & 29 & 47 & 91 \\
All families & 48 & 69 & 72 & 41 & 80 & 69 & 190 \\
\hline
\end{tabular}

1022

1023

1024

1025

1026

1027

1028

1029

1030

1031

1032

1033

1034

1035

1036

1037

1038

1039

1040

1041

1042

1043

1044

1045

1046

1047

1048

1049

1050

1051

1052

1053 
1054 Table 2. The number of individuals from each beetle family, and all families combined, 1055 collected in bamboo forests, terra firme forests, dry season, wet season. The last column lists 1056 the total number of individuals collected within each family and all for all families combined. 1057

\begin{tabular}{lccccc}
\hline Abundance & Bamboo & Terra Firme & Dry & Wet & $\begin{array}{c}\text { Total no. } \\
\text { individuals }\end{array}$ \\
\hline Carabidae & 51 & 52 & 16 & 87 & 103 \\
Curculionidae & 62 & 93 & 71 & 84 & 155 \\
Histeridae & 153 & 228 & 204 & 177 & 381 \\
Scarabaeidae & 1273 & 1840 & 1677 & 1436 & 3113 \\
All families & 1539 & 2213 & 1968 & 1784 & 3752 \\
\hline
\end{tabular}

1059

1060

1061

1062

1063

1064

1065

1066

1067

1068

1069

1070

1071

1072

1073

1074

1075

1076

1077

1078

1079

1080

1081

1082

1083

1084

1085

1086

1087

1088

1089

1090

1091

1092

1093 
1094 Table 3. Beetle species contributing $90 \%$ of the total number of individuals collected in each 1095 habitat (SIMPER - PRIMER 6.0). The values represent the percent contribution of each species 1096 to the distinctness in beetle community structure between bamboo and terra firme forest. The 1097 largest numbers are associated with species that most greatly distinguish assemblages in one 1098 forest type or another.

1099

\begin{tabular}{|c|c|c|}
\hline Species & Bamboo & Terra Firme \\
\hline \multicolumn{3}{|l|}{ Carabidae } \\
\hline Odontocheila cayennensis & 0 & 1.89 \\
\hline \multicolumn{3}{|l|}{ Curculionidae } \\
\hline Curculionidae 13 & 0 & 0.96 \\
\hline \multicolumn{3}{|l|}{ Histeridae } \\
\hline Omolodes A & 6.71 & 8.35 \\
\hline Phelister B & 2.1 & 5.62 \\
\hline Operclipygus $C$ & 1.66 & 0 \\
\hline \multicolumn{3}{|l|}{ Scarabaeidae } \\
\hline Enema pan & 14.8 & 0 \\
\hline Scybalocanthon C & 12.63 & 8.51 \\
\hline Canthidium $A$ & 9.59 & 3.04 \\
\hline Onthophagus xanthomerus & 9.4 & 10.96 \\
\hline Canthidium $F$ & 6.1 & 2.33 \\
\hline Canthidium gerstaeckeri & 5.28 & 3.31 \\
\hline Dichotomius ohausi & 5.03 & 6.51 \\
\hline Dichotomius batesi & 4.87 & 0 \\
\hline Dichotomius nr. lucasi & 3.57 & 3.34 \\
\hline Canthonella D & 3.05 & 0 \\
\hline Scybalocanthon D & 2.06 & 5.2 \\
\hline Canthidium nr. deyrollei & 1.66 & 2.75 \\
\hline Dichotomius lucasi & 1.58 & 3.09 \\
\hline Ateuchus $C$ & 0 & 7.21 \\
\hline Ateuchus D & 0 & 3.11 \\
\hline Canthidium batesi & 0 & 7.84 \\
\hline Ceratocanthinae A & 0 & 1.4 \\
\hline Deltochilum nr. komerecki & 0 & 1.19 \\
\hline Eurysternus nov. stigilatus & 0 & 3.72 \\
\hline
\end{tabular}

